\title{
Secondary organic aerosol (SOA) formation from reaction of isoprene with nitrate radicals $\left(\mathrm{NO}_{3}\right)$
}

\author{
N. L. Ng ${ }^{1}$, A. J. Kwan ${ }^{2}$, J. D. Surratt ${ }^{1}$, A. W. H. Chan ${ }^{1}$, P. S. Chhabra ${ }^{1}$, A. Sorooshian ${ }^{1}$, H. O. T. Pye ${ }^{1}$, J. D. Crounse ${ }^{1}$, \\ P. O. Wennberg ${ }^{2,3}$, R. C. Flagan ${ }^{1,2}$, and J. H. Seinfeld ${ }^{1,2}$ \\ ${ }^{1}$ Division of Chemistry and Chemical Engineering, California Institute of Technology, Pasadena, CA 91125, USA \\ ${ }^{2}$ Division of Engineering and Applied Science, California Institute of Technology, Pasadena, CA 91125, USA \\ ${ }^{3}$ Division of Geological and Planetary Sciences, California Institute of Technology, Pasadena, CA 91125, USA
}

Received: 3 January 2008 - Published in Atmos. Chem. Phys. Discuss.: 15 February 2008

Revised: 3 July 2008 - Accepted: 3 July 2008 - Published: 1 August 2008

\begin{abstract}
Secondary organic aerosol (SOA) formation from the reaction of isoprene with nitrate radicals $\left(\mathrm{NO}_{3}\right)$ is investigated in the Caltech indoor chambers. Experiments are performed in the dark and under dry conditions $(\mathrm{RH}<10 \%)$ using $\mathrm{N}_{2} \mathrm{O}_{5}$ as a source of $\mathrm{NO}_{3}$ radicals. For an initial isoprene concentration of 18.4 to $101.6 \mathrm{ppb}$, the SOA yield (defined as the ratio of the mass of organic aerosol formed to the mass of parent hydrocarbon reacted) ranges from $4.3 \%$ to $23.8 \%$. By examining the time evolutions of gas-phase intermediate products and aerosol volume in real time, we are able to constrain the chemistry that leads to the formation of lowvolatility products. Although the formation of ROOR from the reaction of two peroxy radicals $\left(\mathrm{RO}_{2}\right)$ has generally been considered as a minor channel, based on the gas-phase and aerosol-phase data it appears that $\mathrm{RO}_{2}+\mathrm{RO}_{2}$ reaction (self reaction or cross-reaction) in the gas phase yielding ROOR products is a dominant SOA formation pathway. A wide array of organic nitrates and peroxides are identified in the aerosol formed and mechanisms for SOA formation are proposed. Using a uniform SOA yield of $10 \%$ (corresponding to $\mathrm{M}_{o} \cong 10 \mu \mathrm{g} \mathrm{m}^{-3}$ ), it is estimated that $\sim 2$ to $3 \mathrm{Tg} \mathrm{yr}^{-1}$ of $\mathrm{SOA}$ results from isoprene+ $\mathrm{NO}_{3}$. The extent to which the results from this study can be applied to conditions in the atmosphere depends on the fate of peroxy radicals in the nighttime troposphere.
\end{abstract}

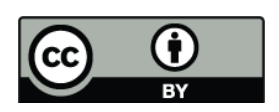

Correspondence to: J. H. Seinfeld (seinfeld@caltech.edu)

\section{Introduction}

Isoprene is the most abundant non-methane hydrocarbon emitted into the atmosphere with a global emission of $\sim 500 \mathrm{Tg} \mathrm{yr}^{-1}$ (Guenther et al., 1995; Guenther et al., 2006). In the troposphere, isoprene reacts with hydroxyl radicals $(\mathrm{OH})$, ozone $\left(\mathrm{O}_{3}\right)$, and nitrate radicals $\left(\mathrm{NO}_{3}\right)$. Owing to its high concentration and reactivity with $\mathrm{OH}$ radicals, isoprene plays an important role in the photochemistry occurring within the atmospheric boundary layer. Recently, it has been shown that the photooxidation of isoprene leads to the formation of low volatility species that condense to form SOA (Claeys et al., 2004; Edney et al., 2005; Kroll et al., 2005; Dommen et al., 2006; Kroll et al., 2006; Surratt et al., 2006); SOA yields as high as $\sim 3 \%$ have been observed (Kroll et al., 2005; Kroll et al., 2006). Global SOA production from isoprene photooxidation has been estimated to be about $13 \mathrm{Tg} \mathrm{yr}^{-1}$ (Henze et al., 2007).

Although emission of isoprene from vegetation is triggered by sunlight and increases with light intensity and temperature (e.g. Sharkey et al., 1996), the isoprene mixing ratio has been observed to peak in early evening in several field studies, with a measured mixing ratio up to a few ppb (Curren et al., 1998; Starn et al., 1998; Stroud et al., 2002; Steinbacher et al., 2005). After sunset, the isoprene mixing ratio drops rapidly, and it has been suggested that the reaction with nitrate radicals, $\mathrm{NO}_{3}$, is a major contributor to isoprene decay at night (Curren et al., 1998; Starn et al., 1998; Stroud et al., 2002; Steinbacher et al., 2005). Typical $\mathrm{NO}_{3}$ radical mixing ratios in boundary layer continental air masses range between $\sim 10$ to $\sim 100$ ppt (Platt and Janssen, 1995; Smith et al., 1995; Heintz et al., 1996; Carslaw et al., 1997). However, concentrations as high as

Published by Copernicus Publications on behalf of the European Geosciences Union. 
several hundred ppt have been observed over northeastern USA and Europe (Platt et al., 1981; von Friedeburg et al., 2002; Brown et al., 2006; Penkett et al., 2007). Given the rapid reaction rate between isoprene and $\mathrm{NO}_{3}$ radicals ( $k_{\mathrm{NO}_{3}}=7 \times 10^{-13} \mathrm{~cm}^{3}$ molecule ${ }^{-1} \mathrm{~s}^{-1}$ at $T=298 \mathrm{~K}$, IUPAC), it is likely that $\mathrm{NO}_{3}$ radicals play a major role in the nighttime chemistry of isoprene.

The kinetics and gas-phase products of the isoprene- $\mathrm{NO}_{3}$ reaction have been the subject of several laboratory and theoretical studies (Jay and Stieglitz, 1989; Barnes et al., 1990; Skov et al., 1992; Kwok et al., 1996; Berndt and Böge, 1997; Suh et al., 2001; Zhang et al., 2002; Fan et al., 2004). In many studies, $\mathrm{C}_{5}$-nitrooxycarbonyl is identified as the major first-generation gas-phase reaction product (Jay and Stieglitz, 1989; Skov et al., 1992; Kwok et al., 1996; Berndt and Böge, 1997). Other compounds such as $C_{5}$-hydroxynitrate, $C_{5}$ nitrooxyhydroperoxide, and $\mathrm{C}_{5}$-hydroxycarbonyl have also been identified (Kwok et al., 1996); $\mathrm{C}_{5}$-hydroxynitrate has also been measured in ambient air with concentrations in the lower ppt range at a few $\mathrm{ng} \mathrm{m}^{-3}$ (Werner et al., 1999). According to the experimental study by Barnes et al. (1990), the yield for nitrate-containing compounds from the reaction of isoprene and $\mathrm{NO}_{3}$ radicals can be as high as $80 \%$. A recent modeling study in conjunction with observations from the ICARTT field campaign suggests that $\sim 50 \%$ of the total isoprene nitrates production occurs via reaction of isoprene and $\mathrm{NO}_{3}$ radicals (Horowitz et al., 2007).

Little is known beyond the formation of the firstgeneration products of the reaction of $\mathrm{NO}_{3}$ with isoprene. The isoprene nitrates and other first-generation products still contain a double bond, and it is likely that the further oxidation of these species will lead to low volatility products that can contribute to SOA formation at nighttime.

In this work, SOA formation from the reaction of isoprene with $\mathrm{NO}_{3}$ radicals is investigated. Laboratory chamber experiments are performed in the dark using $\mathrm{N}_{2} \mathrm{O}_{5}$ as a source of $\mathrm{NO}_{3}$ radicals. Aerosol yields are obtained over a range of initial isoprene concentrations (mixing ratios). By examining the time evolutions of aerosol volume and different intermediate gas-phase products, we are able to constrain the chemistry that leads to the formation of low-volatility products. Mechanisms for SOA formation are proposed and chemical composition data of the SOA formed are also presented.

\section{Experimental section}

Experiments are carried out in the Caltech dual $28 \mathrm{~m}^{3}$ Teflon chambers. A detailed description of the facility is provided elsewhere (Cocker et al., 2001; Keywood et al., 2004). Before each experiment, the chambers are flushed continuously for over $24 \mathrm{~h}$. Aerosol number concentration, size distribution, and volume concentration are measured by a Differential Mobility Analyzer (DMA, TSI model 3081) coupled with a condensation nucleus counter (TSI model 3760).
All aerosol growth data are corrected for wall loss, in which size-dependent particle loss coefficients are determined from inert particle wall loss experiments (Keywood et al., 2004). Temperature, relative humidity $(\mathrm{RH}), \mathrm{O}_{3}, \mathrm{NO}$, and $\mathrm{NO}_{\mathrm{x}}$ are continuously monitored. Experiments are performed in the dark at room temperature $\left(20-21^{\circ} \mathrm{C}\right)$ and under dry conditions $(\mathrm{RH}<10 \%)$.

In most experiments, seed aerosols are introduced into the chamber to act as a substrate onto which the gas-phase products may condense. Seed aerosols are generated by atomizing an aqueous solution with a constant-rate atomizer. The seed solution consists of $0.015 \mathrm{M}\left(\mathrm{NH}_{4}\right)_{2} \mathrm{SO}_{4}$. In a few experiments, acidic seed is used, consisting of 0.03 $\mathrm{M} \mathrm{MgSO}_{4}$ and $0.05 \mathrm{MH}_{2} \mathrm{SO}_{4}$. The initial particle number concentration is $\sim 20000$ particles $\mathrm{cm}^{-3}$, with a geometric mean diameter of $\sim 50 \mathrm{~nm}$. The initial seed volume is $10-$ $12 \mu \mathrm{m}^{3} \mathrm{~cm}^{-3}$. In some experiments, no seed particles are added and aerosols are formed via nucleation. After introduction of the seed aerosols (in seeded experiments), a known volume of isoprene (Aldrich, 99\%) is injected into a glass bulb and introduced into the chamber by an air stream. The mixing ratio of isoprene is monitored with a gas chromatograph equipped with a flame ionization detector (GC-FID, Agilent model 6890N). The column used is a bonded polystyrene-divinylbenzene based column (HPPLOT Q, $15 \mathrm{~m} \times 0.53 \mathrm{~mm}, 40 \mu \mathrm{m}$ thickness, J\&W Scientific). The oven temperature is held at $60^{\circ} \mathrm{C}$ for $0.5 \mathrm{~min}$, ramped at $35^{\circ} \mathrm{C} \min ^{-1}$ to $200^{\circ} \mathrm{C}$, and held constant for $3.5 \mathrm{~min}$.

The thermal decomposition of $\mathrm{N}_{2} \mathrm{O}_{5}$ serves as a source of $\mathrm{NO}_{3}$ radicals in these experiments. $\mathrm{N}_{2} \mathrm{O}_{5}$ is prepared and collected offline by mixing a stream of nitric oxide $(\geq 99.5 \%$, Matheson Tri Gas) with a stream of ozone in a glass bulb (Davidson et al., 1978):

$$
\begin{aligned}
& \mathrm{NO}+\mathrm{O}_{3} \rightarrow \mathrm{NO}_{2}+\mathrm{O}_{2} \\
& \mathrm{NO}_{2}+\mathrm{O}_{3} \rightarrow \mathrm{NO}_{3}+\mathrm{O}_{2} \\
& \mathrm{NO}_{2}+\mathrm{NO}_{3} \leftrightarrow \mathrm{N}_{2} \mathrm{O}_{5}
\end{aligned}
$$

Ozone is generated by flowing oxygen through an ozonizer (OREC model V10-0, Phoenix, AZ) at $\sim 1 \mathrm{~L} \mathrm{~min}^{-1}$. The mixing ratio of ozone is measured by a UV/VIS spectrometer (Hewlett Packard model 8453 ) to be $\sim 2 \%$. The flow rate of nitric oxide into the glass bulb is adjusted until the brown color in the bulb disappears. The $\mathrm{N}_{2} \mathrm{O}_{5}$ is trapped for $2 \mathrm{~h}$ in an acetone-dry ice bath (approximately at $-80^{\circ} \mathrm{C}$; cold enough to trap $\mathrm{N}_{2} \mathrm{O}_{5}$ but not $\mathrm{O}_{3}$, as condensed $\mathrm{O}_{3}$ can explode upon warming and is extremely dangerous) as a white solid, and stored between experiments under liquid nitrogen temperature. Once the seed and isoprene concentrations in the chamber stabilize, reaction is initiated by vaporizing $\mathrm{N}_{2} \mathrm{O}_{5}$ into an evacuated $500 \mathrm{~mL}$ glass bulb and introduced into the chamber with an air stream of $5 \mathrm{~L} \mathrm{~min}^{-1}$. 
The amount of $\mathrm{N}_{2} \mathrm{O}_{5}$ injected is estimated based on the vapor pressure in the glass bulb, which is measured using a capacitance manometer (MKS); this amount corresponds to an initial mixing ratio of $\sim 1 \mathrm{ppm}$ in the chamber. The thermal decomposition of $\mathrm{N}_{2} \mathrm{O}_{5}$ forms $\mathrm{NO}_{2}$ and $\mathrm{NO}_{3}$ radicals. Impurities in the $\mathrm{N}_{2} \mathrm{O}_{5}$ starting material are quantified by FTIR spectroscopy (Nicolet model Magna 550). $\mathrm{N}_{2} \mathrm{O}_{5}$ is vaporized into an evacuated pyrex cell $\left(18 \mathrm{~cm}\right.$ in length and $\left.300 \mathrm{~cm}^{3}\right)$ with $\mathrm{CaF}_{2}$ windows. Spectra are collected immediately upon addition over the $1000 \mathrm{~cm}^{-1}$ to $4000 \mathrm{~cm}^{-1}$ window allowing for quantification of $\mathrm{NO}_{2}\left(1616 \mathrm{~cm}^{-1}\right.$ band $)$ and $\mathrm{HNO}_{3}$ (3550 $\mathrm{cm}^{-1}$ band) impurities.

A custom-modified Varian 1200 Chemical Ionization Mass Spectrometer (CIMS) is used to continuously monitor the concentrations of various gas-phase intermediates and products over the course of the experiments. The CIMS instrument is operated mainly in negative mode using $\mathrm{CF}_{3} \mathrm{O}^{-}$ as a reagent ion, which selectively clusters with compounds having high fluorine affinity (e.g., acidic compounds and many hydroxy- and nitrooxy- carbonyls), forming ions at $m / z$ MW +85 . In some experiments, the CIMS instrument is also operated in the positive mode using $\mathrm{H}_{2} \mathrm{O}$ as a reagent ion forming ions at $m / z \mathrm{MW}+1$. The ionization schemes are as follows:

Negative chemical ionization: $\mathrm{CF}_{3} \mathrm{O}^{-}+\mathrm{HB}->\mathrm{CF}_{3} \mathrm{O}^{-} \cdot \mathrm{HB}$ Positive chemical ionization: $\mathrm{H}_{3} \mathrm{O}^{+}+\mathrm{D}->\mathrm{D} \cdot \mathrm{H}^{+}+\mathrm{H}_{2} \mathrm{O}$ (where D has a proton affinity $>\mathrm{H}_{2} \mathrm{O}$ )

The term "product ion" is used throughout this manuscript to describe the ionized products formed through the above chemical reaction schemes. Typically, we scan from $m / z 50$ to 400 . More details about the CIMS technique are given in Crounse et al. (2006) and $\mathrm{Ng}$ et al. (2007a). Because authentic standards are not available for the major products, sensitivities are not experimentally determined. We estimate the collision rate of $\mathrm{CF}_{3} \mathrm{O}^{-}$with these products (which determines the sensitivity) with the empirical method of $\mathrm{Su}$ and Chesnavich (1982), which bases its predictions on an analyte's dipole moment and polarizability. Dipole moments and polarizabilities are calculated with the Spartan06 quantum package, and are based on molecular structures optimized with the B3LYP/6-31G(d) method. Further details on estimating CIMS sensitivities based on quantum calculations are described in Paulot et al. (2008). As isomers would have different polarities and hence different sensitivities, in estimating the concentrations it is assumed that the $\mathrm{NO}_{3}$ attack at $\mathrm{C}_{1}$-position to $\mathrm{C}_{4}$-position is 5.5:1 (See Sect. 4.1).

Aerosol physical and chemical properties are monitored by many instruments. Real-time particle mass spectra are obtained with an Aerodyne quadrupole Aerosol Mass Spectrometer (Q-AMS) (Jayne et al., 2000). A Particle-IntoLiquid Sampler (PILS, Brechtel Manufacturing, Inc.) coupled with ion chromatography (IC) is employed for quantitative measurements of water-soluble ions in the aerosol phase
(Sorooshian et al., 2006). Duplicate Teflon filters (PALL Life Sciences, $47-\mathrm{mm}$ diameter, $1.0-\mu \mathrm{m}$ pore size, teflo membrane) are collected from a selected number of experiments for offline chemical analysis. Filter sampling is initiated when the aerosol volume reaches its maximum value. Depending on the total volume concentration of aerosol in the chamber, the filter sampling time is $2-4 \mathrm{~h}$, which results in $\sim 2-5 \mathrm{~m}^{3}$ of total chamber air sampled. Teflon filters used for high-resolution electrospray ionization-time-of-flight mass spectrometry (ESI-TOFMS) analysis are extracted in $5 \mathrm{~mL}$ of high-purity methanol (LC-MS CHROMASOLV-Grade, Sigma-Aldrich) by $45 \mathrm{~min}$ of sonication. Methanol sample extracts are then blown dry under a gentle $\mathrm{N}_{2}$ stream (without added heat) once the filters are removed and archived at $-20^{\circ} \mathrm{C}$. Dried residues are then reconstituted with $500 \mathrm{~mL}$ of a $1: 1(\mathrm{v} / \mathrm{v})$ solvent mixture of $0.1 \%$ acetic acid in water (LC-MS CHROMASOLV-Grade, Sigma-Aldrich) and $0.1 \%$ acetic acid in methanol (LC-MS CHROMASOLV-Grade, Sigma Aldrich). All resultant filter extracts are analyzed by a Waters ACQUITY ultra performance liquid chromatography (UPLC) system, coupled to a Waters LCT Premier XT timeof-flight mass spectrometer (TOFMS) equipped with an ESI source that is operated in the negative (-) ionization mode. Detailed operating conditions for the UPLC/(-)ESI-TOFMS instrument have been described previously ( $\mathrm{Ng}$ et al., 2007a). A Waters ACQUITY UPLC HSS column is selected to separate the SOA components because of its increased retention of water-soluble polar organics; separation is achieved as a result of trifunctionally-bonded (T3) $\mathrm{C}_{18}$ alkyl residues on this column, which prevent stationary phase collapse when a $100 \%$ aqueous mobile phase is used and result in better retention of water-soluble polar organic compounds. In addition to the UPLC/(-)ESI-TOFMS analysis, all remaining Teflon filters are extracted and analyzed for total peroxide content (sum of ROOR and ROOH) by using an iodometricspectroscopic method (Docherty et al., 2005; Surratt et al., 2006).

To study the mechanism of SOA formation, in several experiments the experimental protocols are slightly modified: (1) An excess amount of isoprene (relative to $\mathrm{N}_{2} \mathrm{O}_{5}$ concentration) is injected into the chamber to prevent the further reaction of first-generation gas-phase products, allowing these products to be detected more readily; (2) After the addition of isoprene, pulses of $\mathrm{N}_{2} \mathrm{O}_{5}$ are introduced into the chamber to study the evolution of different intermediate gas-phase products; (3) With isoprene well mixed in the chamber, $\mathrm{N}_{2} \mathrm{O}_{5}$ is introduced slowly to maximize the self-reaction of peroxy radicals (see Sect. 4.2). This is achieved by first injecting $\mathrm{N}_{2} \mathrm{O}_{5}$ into a $65 \mathrm{~L}$ Teflon bag; then an air stream of $1 \mathrm{~L} \mathrm{~min}^{-1}$ is passed through the Teflon bag to introduce $\mathrm{N}_{2} \mathrm{O}_{5}$ into the chamber over a $7 \mathrm{~h}$ period. We refer to this as the "slow $\mathrm{N}_{2} \mathrm{O}_{5}$ injection experiment"; and (4) With $\mathrm{N}_{2} \mathrm{O}_{5}$ well mixed in the chamber, isoprene is introduced slowly to maximize the reaction between peroxy radicals and nitrate radicals (see Sect. 4.2). This is achieved by first injecting isoprene into a 


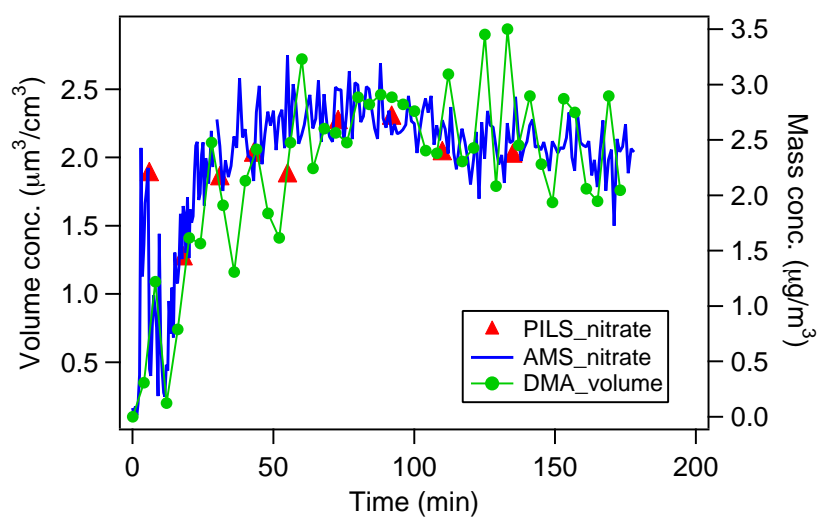

Fig. 1. Time profiles of aerosol volume, inorganic nitrate measured by PILS/IC, and nitrate signals from Q-AMS in a blank experiment ( $\sim 1 \mathrm{ppm} \mathrm{N}_{2} \mathrm{O}_{5}$, ammonium sulfate seed, no isoprene).

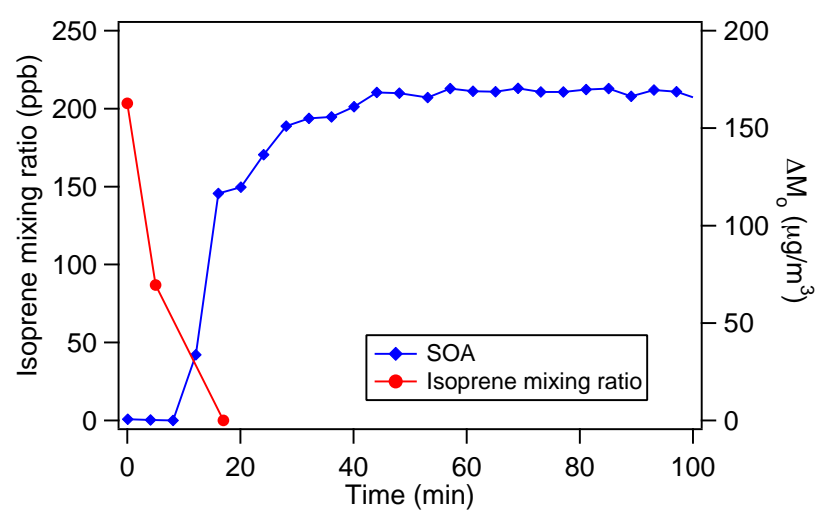

Fig. 2. Reaction profile of the oxidation of an initial mixture containing $203.4 \mathrm{ppb}$ isoprene $\left(573 \mu \mathrm{g} / \mathrm{m}^{3}\right)$.

$65 \mathrm{~L}$ Teflon bag, and then introduced into the chamber with an air stream of $1 \mathrm{~L} \mathrm{~min}^{-1}$ for $7 \mathrm{~h}$. We refer to this as the "slow isoprene injection experiment".

Experimental conditions and results are given in Table 1. In calculating SOA yield (defined as the ratio of the organic aerosol mass formed to the mass of parent hydrocarbon reacted), knowledge of the SOA density is required. By comparing volume distributions from the DMA and mass distributions from the Q-AMS, the effective density for the SOA formed can be estimated (Bahreini et al., 2005; Alfarra et al., 2006).

\section{Results}

\subsection{Blank experiments}

Blank experiments are performed to ensure that the aerosol growth observed is from the reaction of isoprene with $\mathrm{NO}_{3}$ radicals. In these experiments, $\sim 1 \mathrm{ppm} \mathrm{N}_{2} \mathrm{O}_{5}$ is introduced

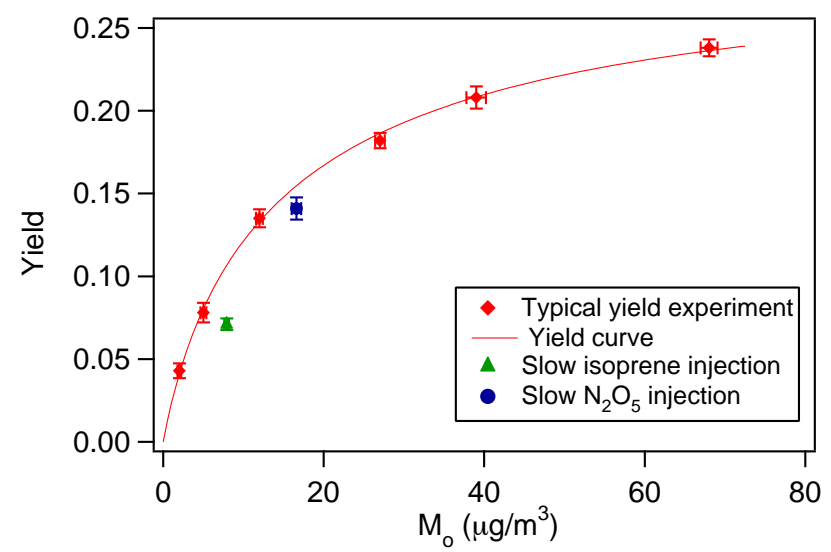

Fig. 3. SOA yield data and yield curve for isoprene- $\mathrm{NO}_{3}$ reaction. Also shown are SOA yields from the slow $\mathrm{N}_{2} \mathrm{O}_{5}$ injection experiment and slow isoprene injection experiment.

into chamber after the addition of ammonium sulfate seed aerosol (with no isoprene present). As shown in Fig. 1, aerosol volume increases by $\sim 2 \mu \mathrm{m}^{3} \mathrm{~cm}^{-3}$ within an hour after the introduction of $\mathrm{N}_{2} \mathrm{O}_{5}$. About $2.5 \mu \mathrm{g} \mathrm{m}^{-3}$ of inorganic nitrate is measured by PILS/IC, which agrees well with the amount of nitrates detected by Q-AMS. FTIR analysis indicates the presence of $\sim 10 \% \mathrm{HNO}_{3}$ and $4 \% \mathrm{NO}_{2}$ impurity in the $\mathrm{N}_{2} \mathrm{O}_{5}$ prepared, thus the nitrates measured by PILS/IC and Q-AMS likely arise from the partitioning or reactive uptake of gas-phase $\mathrm{HNO}_{3}$ into the aerosol phase, or $\mathrm{HNO}_{3}$ produced from heterogeneous hydrolysis of $\mathrm{N}_{2} \mathrm{O}_{5}$. As in the Q-AMS analysis, no organic species are detected in the filter samples collected from these blank experiments.

\subsection{Aerosol yields}

A series of experiments with different initial isoprene concentrations are carried out (these are referred to as "typical yield experiments" hereafter). The initial isoprene concentration ranged from 18.4 to $203.4 \mathrm{ppb}$. Figure 2 shows the reaction profile of the oxidation of an initial mixture containing $203.4 \mathrm{ppb}$ isoprene. Since the chamber is $\mathrm{NO}_{\mathrm{x}}$-free at the beginning of the experiment, once $\mathrm{N}_{2} \mathrm{O}_{5}$ is introduced into the chamber the equilibrium in Reaction (3) favors the formation of $\mathrm{NO}_{3}$. This generates a relatively high concentration of $\mathrm{NO}_{3}$ radicals and results in rapid isoprene decay. Aerosol growth is observed and aerosol volume continues to increase even after all the isoprene is consumed. Owing to the rapid isoprene decay and the relatively long time between each GC measurement (12 min), the isoprene decay over time is captured only in experiments in which the initial isoprene concentration is $>100 \mathrm{ppb}$. Based on the observed isoprene decay in these experiments and the isoprene- $\mathrm{NO}_{3}$ rate constant $k_{\mathrm{NO}_{3}}$, the average $\mathrm{NO}_{3}$ concentration in the chamber is estimated to be $\sim 140$ ppt. 
Table 1. Initial conditions and results for yield experiments.

\begin{tabular}{llllll}
\hline Date & $\mathrm{T}(\mathrm{K})$ & $\mathrm{RH}(\%)$ & $\Delta \mathrm{HC}(\mathrm{ppb})^{\mathrm{a}}$ & $\Delta \mathrm{M}_{o}\left(\mu \mathrm{g} / \mathrm{m}^{3}\right)^{\mathrm{b}}$ & SOA Yield $(\%)$ \\
\hline $8 / 9 / 07$ & 294 & 5.1 & $101.6 \pm 0.6$ & $68.1 \pm 1.1$ & $23.8 \pm 0.5$ \\
$8 / 10 / 07$ & 293 & 4.7 & $30.2 \pm 0.1$ & $11.5 \pm 0.4$ & $13.5 \pm 0.5$ \\
$8 / 11 / 07$ & 294 & 5.4 & $67.1 \pm 0.1$ & $39.3 \pm 1.2$ & $20.8 \pm 0.7$ \\
$8 / 12 / 07$ & 293 & 6.0 & $51.7 \pm 0.2$ & $26.7 \pm 0.6$ & $18.2 \pm 0.5$ \\
$8 / 13 / 07$ & 294 & 5.7 & $18.4 \pm 0.1$ & $2.2 \pm 0.2$ & $4.3 \pm 0.5$ \\
$8 / 14 / 07$ & 294 & 5.5 & $21.8 \pm 0.1$ & $4.8 \pm 0.4$ & $7.8 \pm 0.6$ \\
$10 / 4 / 2007^{\mathrm{c}}$ & 293 & 5.5 & $39.5 \pm 0.1^{\mathrm{d}}$ & $7.9 \pm 0.3$ & $7.1 \pm 0.6$ \\
$10 / 25 / 2007^{\mathrm{e}}$ & 294 & 6.4 & $42.0 \pm 0.1$ & $16.6 \pm 0.6$ & $14.1 \pm 0.7$ \\
\hline
\end{tabular}

a Stated uncertainties $(1 \sigma)$ are from scatter in isoprene measurements.

${ }^{\mathrm{b}}$ Stated uncertainties $(1 \sigma)$ are from scatter in particle volume measurements.

${ }^{\mathrm{c}}$ Slow isoprene injection experiment.

${ }^{\mathrm{d}}$ Concentration estimated based on a separate calibration experiment (see Sect. 3.2); the uncertainty in the measured isoprene concentration is assumed to be the same as in the slow $\mathrm{N}_{2} \mathrm{O}_{5}$ injection experiment.

e Slow $\mathrm{N}_{2} \mathrm{O}_{5}$ injection experiment.

The SOA yield of each experiment (Table 1) is shown in Fig. 3. The density of the SOA is determined to be $1.42 \mathrm{~g} \mathrm{~cm}^{-3}$. The amount of inorganic nitrate detected by PILS/IC in each experiment ranges from 1.6 to $2.6 \mu \mathrm{g} \mathrm{m}^{-3}$, which is approximately equal to that measured in the blank experiments. In calculating SOA yield, the organic aerosol mass is corrected for the amount of inorganic nitrate measured in each experiment. For convenience, SOA yields can be parameterized by a semi-empirical model based on absorptive gas-particle partitioning of two semivolatile products (Odum et al., 1996, 1997a,b):

$Y=\Delta M_{o}\left[\frac{\alpha_{1} K_{o m, 1}}{1+K_{o m, 1} M_{o}}+\frac{\alpha_{2} K_{o m, 2}}{1+K_{o m, 2} M_{o}}\right]$

in which $Y$ is the aerosol yield, $\Delta M_{o}$ is the organic aerosol mass produced, $M_{O}$ is the organic aerosol mass present (equal to $\Delta M_{o}$ in chamber experiments with no absorbing organic mass present initially), $\alpha_{i}$ is the mass-based gasphase stoichiometric fraction for semivolatile species $i$, and $K_{o m, i}$ is the gas-particle partitioning coefficient for species $i$. With this two-product model, Eq. (4) is fit to the experimental yield data (data with $\Delta \mathrm{M}_{o}<100 \mu \mathrm{g} \mathrm{m}^{-3}$ ) and the yield parameters obtained are: $\alpha_{1}=0.089, \alpha_{2}=0.203$, $K_{o m, 1}=0.182 \mathrm{~m}^{3} \mu \mathrm{g}^{-1}$, and $K_{o m, 2}=0.046 \mathrm{~m}^{3} \mu \mathrm{g}^{-1}$. For an organic aerosol mass of $\sim 10 \mu \mathrm{g} \mathrm{m}^{-3}$, the aerosol yield is $\sim 10 \%$.

Also shown in Fig. 3 are aerosol yields from the slow isoprene $/ \mathrm{N}_{2} \mathrm{O}_{5}$ injection experiments. Since the PILS/IC is not employed in these experiments, in calculating SOA yields it is assumed that the amount of inorganic nitrate formed in these slow injection experiments is roughly the same as that in other experiments. For the slow isoprene injection experiment, no isoprene is observed by GC-FID, indicating that once the isoprene enters the chamber, it is quickly consumed by reaction with $\mathrm{NO}_{3}$. The time profile of isoprene

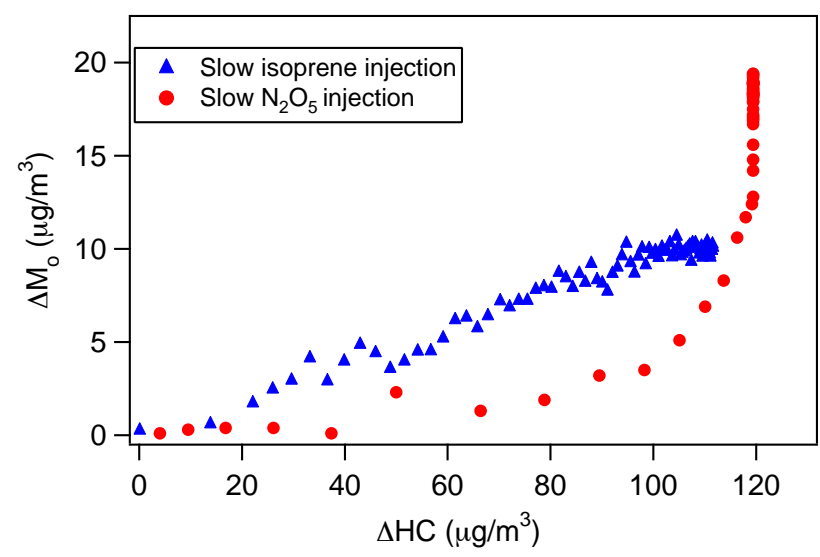

Fig. 4. Time-dependent growth curves for the slow $\mathrm{N}_{2} \mathrm{O}_{5}$ injection experiment and slow isoprene injection experiment (last two experiments in Table 1).

injection is obtained in a separate experiment, in which the same amount of isoprene is added into the chamber without $\mathrm{N}_{2} \mathrm{O}_{5}$ present. Assuming the amount of isoprene injected into the chamber is the same as the isoprene reacted, the amount of isoprene reacted over the course of the slow isoprene experiment can be deduced. As seen in Fig. 3, the SOA yield from the slow $\mathrm{N}_{2} \mathrm{O}_{5}$ injection experiment is roughly the same as those in the other yield experiments; the yield from the slow isoprene injection experiment, however, is lower.

The time-dependent "growth curves" (organic aerosol, $\Delta M_{o}$, as a function of hydrocarbon reacted, $\Delta \mathrm{HC}$ ) over the course of the slow $\mathrm{N}_{2} \mathrm{O}_{5}$ injection experiment and the slow isoprene injection experiment are shown in Fig. 4. As hydrocarbon measurements are made with a lower frequency than particle volume, the isoprene concentrations shown are obtained by interpolating GC-FID measurements. In both 


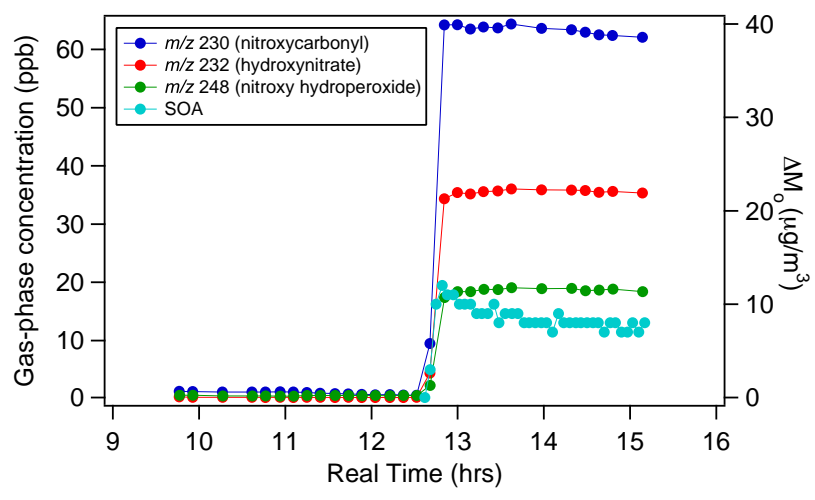

Fig. 5. Time profiles of the major gas-phase products $(\mathrm{m} / \mathrm{z} 230$, 232 , and 248) and the corresponding aerosol growth from the excess isoprene experiment.

experiments about $40 \mathrm{ppb}$ of isoprene is consumed, the only difference being the order of isoprene/ $\mathrm{N}_{2} \mathrm{O}_{5}$ injection. From Fig. 4 it is clear that as the reaction proceeds, more aerosol is formed in the slow isoprene injection experiment for the same amount of isoprene reacted. However, the final SOA yield under the slow $\mathrm{N}_{2} \mathrm{O}_{5}$ injection conditions is higher due to continued aerosol formation even after the complete consumption of isoprene. The presence of a "hook" at the end of the growth curve for the slow $\mathrm{N}_{2} \mathrm{O}_{5}$ injection experiment indicates that further reactions are contributing to aerosol growth after isoprene is consumed ( $\mathrm{Ng}$ et al., 2006). Higher generation products also contribute to the aerosols formed in the slow isoprene injection experiment; however, their contributions are not readily observed in the growth curve owing to the way the experiment is conducted. This is further discussed in Sect. 4.3.

\subsection{Gas-phase measurements}

The CIMS technique measures the concentrations of different gas-phase products over the course of the experiments. A series of experiments is carried out to study the mechanisms of SOA formation by varying the relative amount of isoprene and $\mathrm{N}_{2} \mathrm{O}_{5}$ injected and monitoring the time evolution of the intermediate products. Shown in Fig. 5 are the time profiles of three major gas-phase products and the corresponding aerosol growth from the excess isoprene experiment. In this experiment, $\sim 120 \mathrm{ppb}$ of $\mathrm{N}_{2} \mathrm{O}_{5}$ is first injected into the chamber, followed by the introduction of $\sim 800 \mathrm{ppb}$ isoprene. The initial concentration of isoprene is estimated based on the volume of the isoprene injected and the chamber volume. Once isoprene is injected, a number of product ions are formed immediately, with $m / z$ 230, 232, and 248 being the most dominant ones. Several minor product ions at $m / z$ 185, 377, and 393 are also observed (not shown). With the presence of excess isoprene, it is expected that the three major products detected are first-generation products.

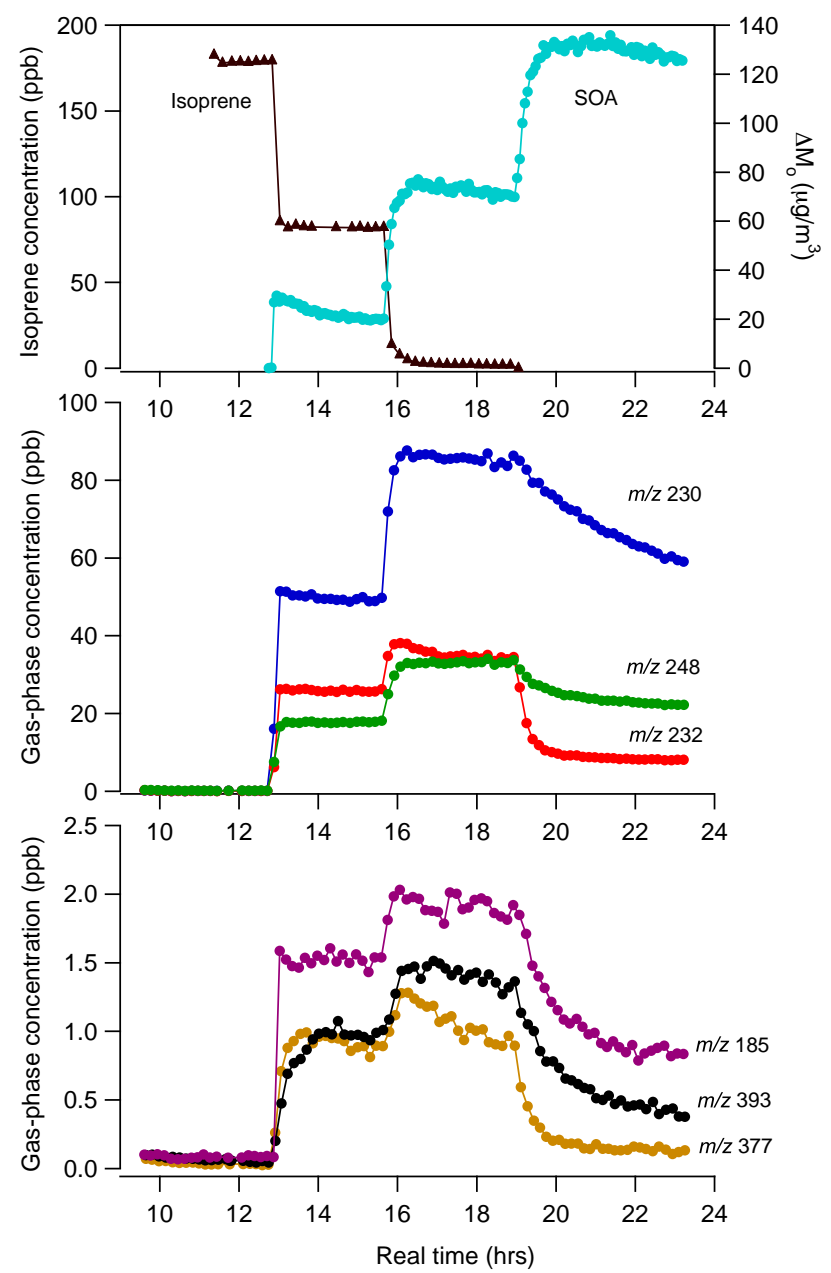

Fig. 6. Time evolution of various gas-phase products in the staggered $\mathrm{N}_{2} \mathrm{O}_{5}$ injection experiment (Isoprene is first injected into the chamber, followed by the addition of 3 pulses of $\mathrm{N}_{2} \mathrm{O}_{5}: \sim 120,50$, and $210 \mathrm{ppb}$ ). The top panel shows the isoprene decay and aerosol formation; the middle panel shows the time profiles of the three major first-generation products $(m / z 230,232$, and 248); the bottom panel shows the time profiles of three minor products $(\mathrm{m} / z 185$, 377, and 393). (The likely identities for these products are shown in Fig. 11).

Their further reaction is suppressed, as indicated by the relatively constant concentrations of the product ions once they are formed. At the end of the experiment, $725 \mathrm{ppb}$ of isoprene is measured by GC-FID. A small amount of aerosol is formed instantaneously, likely from the condensation of relatively nonvolatile first-generation products, or from further generation products that are formed at a relatively rapid rate.

To study further the evolution of the gas-phase products, an experiment is performed in which pulses of $\mathrm{N}_{2} \mathrm{O}_{5}$ are introduced into the chamber (with isoprene present) (Fig. 6). The top panel shows the isoprene decay and aerosol formation; the middle panel shows the time profiles of the three major first-generation products $(m / z 230,232$, and 248); the 


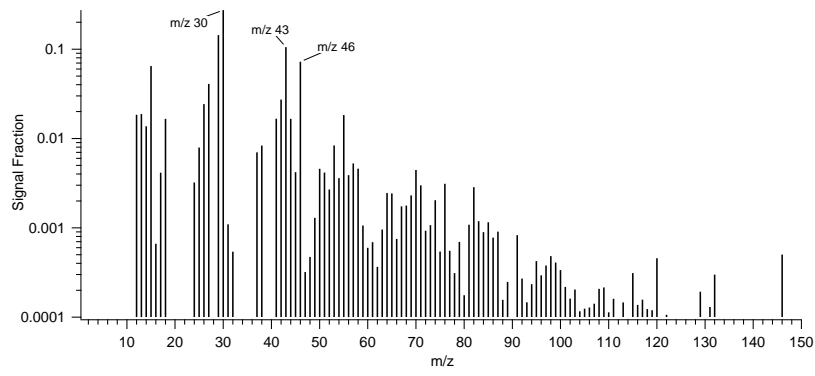

Fig. 7. A typical AMS spectrum for SOA formed in typical yield experiments.

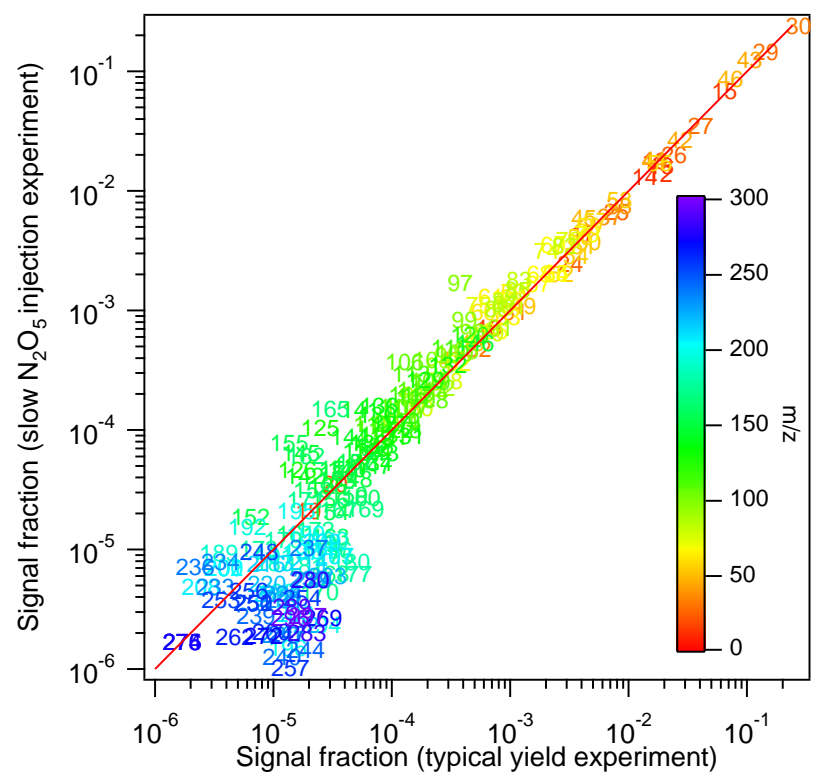

Fig. 8. AMS spectra signal from the slow $\mathrm{N}_{2} \mathrm{O}_{5}$ injection experiment versus a typical yield experiment. Each mass fragment is normalized by the total signal. The solid red line is the $1: 1$ line. Note that the higher masses $(m / z>165)$ are dominated by noise.

bottom panel shows the time profiles of three minor products $(m / z 185,377$, and 393). In this experiment, $179 \mathrm{ppb}$ of isoprene is first injected into the chamber, followed by the addition of 3 pulses of $\mathrm{N}_{2} \mathrm{O}_{5}(\sim 120,50,210 \mathrm{ppb})$. The observations after the addition of the first pulse of $\mathrm{N}_{2} \mathrm{O}_{5}$ are similar to the excess isoprene experiment described above. With the addition of $\sim 120 \mathrm{ppb} \mathrm{N}_{2} \mathrm{O}_{5}, 97 \mathrm{ppb}$ of isoprene is reacted away, $m / z 230,232$, and 248 are formed with concentrations of $49.8 \mathrm{ppb}, 26.1 \mathrm{ppb}$, and $17.3 \mathrm{ppb}$, respectively. Because of the lack of authentic standards, the concentrations are uncertain. Similar to the data in Fig. 5, the concentrations of these product ions stay relatively constant owing to the presence of excess isoprene. The minor products at $m / z$ 185, 377, and 393 , are formed with the concentrations $1.4 \mathrm{ppb}, 0.9 \mathrm{ppb}$, and $0.9 \mathrm{ppb}$, respectively. Because the sum of the ion concentra-

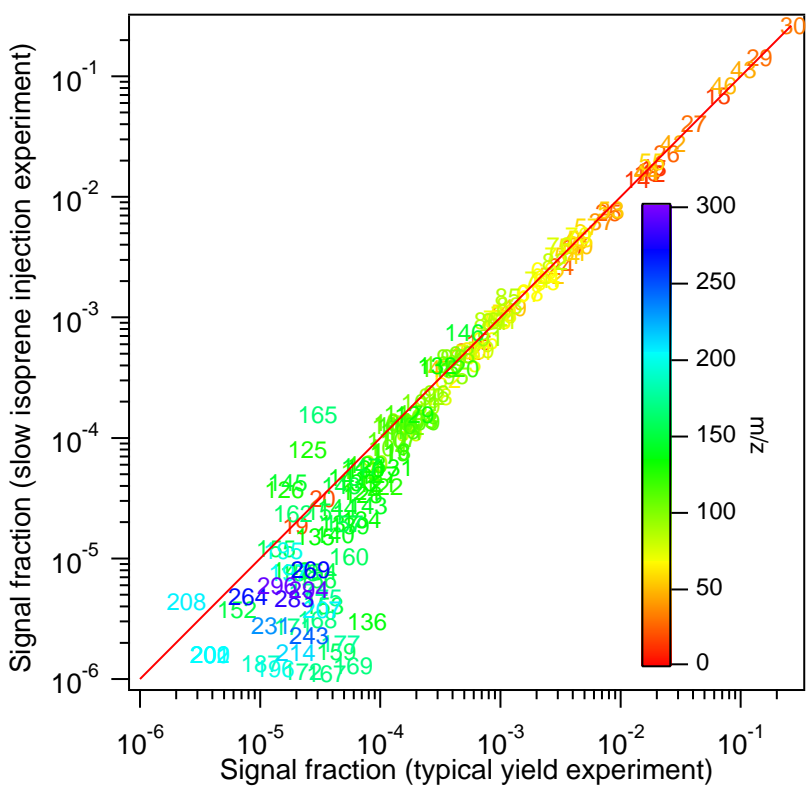

Fig. 9. AMS spectra signal from the slow isoprene injection experiment versus a typical yield experiment. Each mass fragment is normalized by the total signal. The solid red line is the 1:1 line. Note that the higher masses $(m / z>165)$ are dominated by noise.

tions derived from our estimated sensitivities is equal to the reacted isoprene, our estimated sensitivity must represent a lower limit for the actual sensitivity of the CIMS technique to these compounds. It is noted that the $m / z 393$ ion is formed with a relatively slower rate than all other product ions. A small amount of aerosol is observed. At $t=15: 40$, a second pulse of $\mathrm{N}_{2} \mathrm{O}_{5}(\sim 50 \mathrm{ppb})$ is introduced into the chamber and the remaining $82 \mathrm{ppb}$ isoprene is completely consumed. As seen from Fig. 6, the concentrations of all intermediate products increase accordingly and more aerosol is produced. The last pulse of $\mathrm{N}_{2} \mathrm{O}_{5}(\sim 210 \mathrm{ppb})$ is added at $t=19: 00$. Since all isoprene has been consumed, the additional $\mathrm{NO}_{3}$ radicals react mainly with the first-generation products, as indicated by the decay of $m / z 230,232$, and 248, 185, 377, and 393 ions. Of all of the observed products, it appears that $\mathrm{m} / \mathrm{z}$ 232 and 377 ions are the most reactive with $\mathrm{NO}_{3}$ radicals, and their decays in excess $\mathrm{NO}_{3}$ are strongly correlated with aerosol growth. The rest of the product ions display relatively slower decay kinetics. The decay of the major product ion at $m / z 230$ does not appear to correlate with aerosol growth, as the concentration of the $m / z 230$ ion continues to decrease throughout the experiment but there is no further aerosol growth. Since the CIMS instrument has only 0.5 AMU resolution and it cannot distinguish products of similar or identical molecular weight, it is likely that many of observed ions comprise isomers formed from the $\mathrm{NO}_{3}$ attack at different positions. The fact that many of the observed product ions show two distinct decay time scales indicates that these isomers have substantially different reactivity towards $\mathrm{NO}_{3}$ radicals. 


\subsection{Chemical composition of SOA}

\subsubsection{Aerosol Mass Spectrometer (Q-AMS) measurements}

Figure 7 shows the AMS spectrum of SOA formed in the typical yield experiments. Each mass fragment is normalized by the total signal. The SOA exhibits relatively high signals at $\mathrm{m} / \mathrm{z} 30,43$, and 46 . The signals at $\mathrm{m} / \mathrm{z} 30$ and 46 likely correspond to $\mathrm{NO}^{+}(30)$ and $\mathrm{NO}_{2}^{+}(46)$ fragments from the nitrates in the aerosol. The spectrum shown in Fig. 7 is obtained when aerosol volume reaches its maximum value; the spectrum obtained several hours after aerosol volume peaks shows minimal changes in the mass fractions of different fragments, indicating that the aerosol composition is not changing significantly over time.

Figure 8 shows the mass spectrum of the slow $\mathrm{N}_{2} \mathrm{O}_{5}$ injection experiment versus a typical yield experiment; Fig. 9 shows the mass spectrum of the slow isoprene injection experiment versus a typical yield experiment. As shown in both figures, the mass fragments fall on the 1:1 line, suggesting a similar SOA composition under the three different experimental conditions. At higher mass to charge ratios the plots drift below the one-to-one line and it appears that the typical experiments have stronger signals at higher $m / z$ 's. However, the signals at these masses $(>165)$ are strongly dominated by noise and cannot be interpreted as differences between the spectra.

\subsubsection{Offline chemical analysis}

Figure 10 shows the representative UPLC/(-)ESI-TOFMS base peak ion chromatograms (BPCs) for different types of experiments conducted. The numbers denoted above the selected chromatographic peaks correspond to the most abundant negative ions observed in their respective mass spectra. Comparison of the BPCs shown in Fig. 10 indicates that the compositions of the SOA are quite similar for the typical yield experiment, slow isoprene injection experiment, and the acid seed experiment, suggesting a common SOA formation pathway. The SOA composition from the excess isoprene experiment, however, is different from these experiments. This will be discussed further in Sect. 4.4.

Accurate mass measurements for all ions observed by the UPLC/(-)ESI-TOFMS technique for a typical yield experiment are listed in Table 2. The error between the measured mass and theoretical mass is reported in two different ways, ppm and $\mathrm{mDa}$. Overall, the error between the measured and theoretical masses is found to be less than $\pm 2 \mathrm{mDa}$ and $\pm 5 \mathrm{ppm}$, allowing for generally unambiguous identification of molecular formulae. None of the listed ions is observed in solvent blanks and control filters. By combining the elemental SOA composition (i.e. TOFMS suggested ion formula) data and the gas-phase data from CIMS, structures for each of the SOA components are also proposed. As shown in Table 2, the types of compounds formed included nitrooxy-organic acids, hydroxynitrates, nitrooxy-organic peroxides (e.g. nitrooxy-hydroxyperoxides), and nitrooxyorganosulfates. It should be noted that the data presented in Table 2 are also applicable to all other types of experiments conducted in this study; however, none of the organosulfates are observed in the nucleation experiments, consistent with previous work (Liggio et al., 2005; Liggio et al., 2006; Surratt et al., 2007a,b; Iinuma et al., 2007a,b). Surprisingly, previously characterized organosulfates of the 2-methyltetrols and the 2-methyltetrol mono-nitrates detected at $\mathrm{m} / z 215$ and $m / z 260$ (not listed in Table 2), respectively, which are produced from the photooxidation of isoprene in the presence of acidified sulfate seed aerosol (Surratt et al., 2007a,b; GómezGonzález et al., 2007), are also observed in the acid seed experiment shown in Fig. 10, suggesting that nighttime oxidation of isoprene in the presence of acidic seed may also be a viable pathway for these known ambient tracer compounds.

Owing to the implementation of reverse-phase chromatography, the SOA components that are more hydrophilic elute from the column the earliest, while the more hydrophobic components elute the latest. It is clear from Table 2 that compounds with the same carbon number and general functionality (i.e. carboxylic acid, alcohol, or organosulfate), but differing number of nitrooxy groups, exhibit distinctly different chromatographic behaviors. The presence of more nitrooxy groups appears to increase the retention time of the SOA compound. For example, it is found that $m / z 194$ organic acid compound $\left(\mathrm{C}_{5} \mathrm{H}_{8} \mathrm{NO}_{7}^{-}\right)$containing one nitrooxy group elutes earlier than that of the $\mathrm{m} / z 239$ organic acid compounds $\left(\mathrm{C}_{5} \mathrm{H}_{7} \mathrm{~N}_{2} \mathrm{O}_{9}^{-}\right)$containing two nitrooxy groups. Similarly, the $m / z 305$ organosulfate $\left(\mathrm{C}_{5} \mathrm{H}_{9} \mathrm{~N}_{2} \mathrm{O}_{11} \mathrm{~S}^{-}\right)$elutes earlier than that of the $m / z 349$ organosulfate $\left(\mathrm{C}_{5} \mathrm{H}_{8} \mathrm{~N}_{3} \mathrm{O}_{13} \mathrm{~S}^{-}\right)$.

SOA components that are either nitrooxy-organic acids or nitrooxy-organosulfates are detected strongly as the $[\mathrm{M}-\mathrm{H}]^{-}$ ion, consistent with previous work (Surratt et al., 2006; Surratt et al., 2007a,b; Gao et al., 2004a,b; Gao et al., 2006), whereas the hydroxynitrates and nitrooxy-hydroxyperoxides are detected as both the $[\mathrm{M}-\mathrm{H}]^{-}$and $\left[\mathrm{M}-\mathrm{H}+\mathrm{C}_{2} \mathrm{H}_{4} \mathrm{O}_{2}\right]^{-}$ ions, with the latter acetic acid adduct ion, in most cases, being the base peak ion (i.e. dominant ion). The acetic acid adduct ions for the hydroxynitrates and the nitrooxyhydroxyperoxides are formed owing to the presence of acetic acid in the UPLC mobile phase. Previous studies have shown that non-acidic hydroxylated species (such as the 2methyltetrols) and organic peroxides formed from the photooxidation of isoprene (Claeys et al., 2004; Edney et al., 2005; Surratt et al., 2006) are either undetectable or yield weak negative ions when using (-)ESI-MS techniques. However, it appears that the co-presence of nitrooxy groups in the hydroxylated SOA components allow for these compounds to become acidic enough to be detected by the UPLC/(-)ESITOFMS technique, or allow for adduction with acetic acid. Further confirmation for the presence of organic peroxides in the isoprene SOA produced from $\mathrm{NO}_{3}$ oxidation is provided by the iodometric-spectroscopic measurements shown 

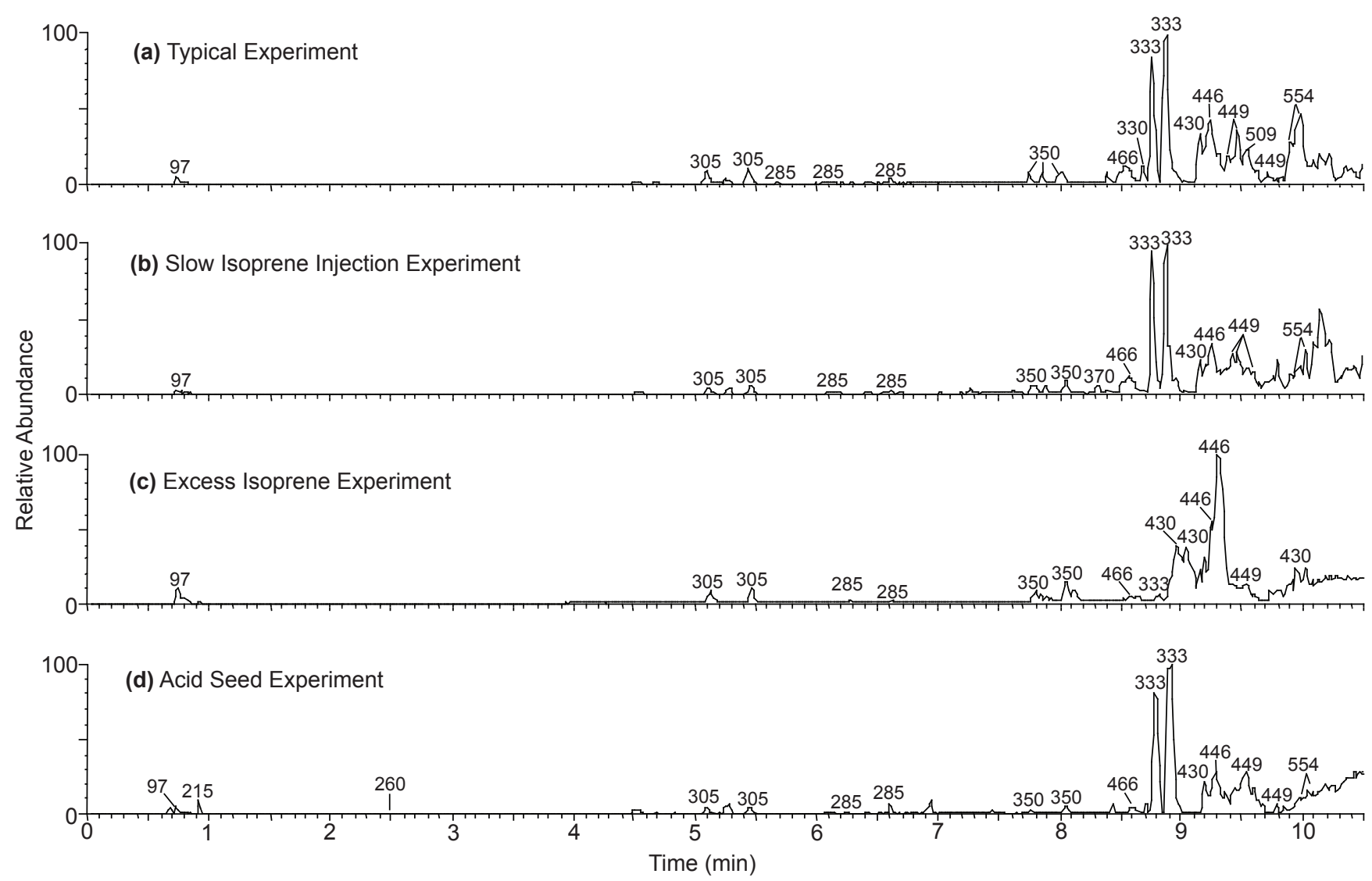

Fig. 10. UPLC/(-)ESI-TOFMS base peak ion chromatograms (BPCs) for the following isoprene- $\mathrm{NO}_{3}$ oxidation experiments: (a) $200 \mathrm{ppb}$ isoprene+1 ppm $\mathrm{N}_{2} \mathrm{O}_{5}$ +seed aerosol generated from $15 \mathrm{mM}\left(\mathrm{NH}_{4}\right)_{2} \mathrm{SO}_{4}$ atomizing solution; (b) $300 \mathrm{ppb}$ isoprene+1 ppm $\mathrm{N}_{2} \mathrm{O}_{5}+$ seed aerosol generated from $15 \mathrm{mM}\left(\mathrm{NH}_{4}\right)_{2} \mathrm{SO}_{4}$ atomizing solution; (c) $1.2 \mathrm{ppm}$ isoprene+700 ppb $\mathrm{N}_{2} \mathrm{O}_{5}+$ seed aerosol generated from $15 \mathrm{mM}$ $\left(\mathrm{NH}_{4}\right)_{2} \mathrm{SO}_{4}$ atomizing solution; (d) $200 \mathrm{ppb}$ isoprene+1 $\mathrm{ppm} \mathrm{N}_{2} \mathrm{O}_{5}$ +seed aerosol generated from $30 \mathrm{mM} \mathrm{MgSO}+50 \mathrm{mM} \mathrm{H}_{2} \mathrm{SO}_{4}$ atomizing solution. The numbers indicated above the selected chromatographic peaks correspond to the most abundant negative ion, which is either the $[\mathrm{M}-\mathrm{H}]^{-}$or $\left[\mathrm{M}-\mathrm{H}+\mathrm{C}_{2} \mathrm{H}_{4} \mathrm{O}_{2}\right]^{-}$ion.

in Table 3. Based upon the UPLC/(-)ESI-TOFMS measurements shown in Table 2, an average molecular weight of 433 for the organic peroxides is assumed for the calculations shown in Table 3. The contribution of organic peroxides to the SOA mass concentration is found to be fairly reproducible for duplicate typical experiments (i.e., 8/22/07 and 10/24/07). The amount of organic peroxides in the excess isoprene experiment is below detection limits. Owing to the lack of authentic standards, there are large uncertainties associated with the quantification of these products in the aerosol phase. This is further discussed in Sect. 4.4.

\section{Gas-phase chemistry and SOA formation}

\subsection{Formation of various gas-phase products}

As seen from Figs. 5 and 6, the three major first-generation products formed from isoprene- $\mathrm{NO}_{3}$ reaction are the $\mathrm{m} / \mathrm{z}$ 230, 232, and 248 ions. Since the CIMS technique uses
$\mathrm{CF}_{3} \mathrm{O}^{-}$(anionic mass $85 \mathrm{Da}$ ) as the reagent ion, compounds are detected at a $m / z$ value of their molecular weight (MW) plus 85. The product ions at $m / z 230,232$, and 248 likely correspond to $\mathrm{C}_{5}$-nitrooxycarbonyl (MW 145), $\mathrm{C}_{5}$ hydroxynitrate (MW 147), and $\mathrm{C}_{5}$-nitrooxyhydroperoxide (MW 163). These products have been observed in previous studies (Jay and Stieglitz, 1989; Skov et al., 1992; Kwok et al., 1996; Berndt and Böge, 1997) and their formation from the isoprene- $\mathrm{NO}_{3}$ reaction is relatively straightforward (Fig. 11). The reaction proceeds by $\mathrm{NO}_{3}$ addition to the $\mathrm{C}=\mathrm{C}$ double bond, forming four possible nitrooxyalkyl radicals depending the position of the $\mathrm{NO}_{3}$ attack. Previous studies suggest that $\mathrm{NO}_{3}$ radicals predominantly attack isoprene in the 1-position, with a branching ratio $\left(\mathrm{C}_{1}\right.$-position/ $\mathrm{C}_{4}$ position) varying between 3.5 and 7.4 (Skov et al., 1992; Berndt and Boge, 1997; Suh et al., 2001). As mentioned before, the average branching ratio (5.5:1) is used in estimating the sensitivities of the compounds measured by CIMS. In Fig. 11, only the nitrooxyalkyl radical formed from the $\mathrm{C} 1$ 
Table 2. SOA products identified using UPLC/(-)ESI-TOFMS.

\begin{tabular}{|c|c|c|c|c|c|c|c|}
\hline $\begin{array}{l}\text { Retention Time } \\
(\mathrm{min})\end{array}$ & $\begin{array}{l}\text { Measured } \\
{[\mathrm{M}-\mathrm{H}]^{-} \text {Ion }(m / z)}\end{array}$ & $\begin{array}{l}\text { TOFMS Suggested } \\
{[\mathrm{M}-\mathrm{H}]^{-} \text {Ion Formula }}\end{array}$ & $\begin{array}{l}\text { Error } \\
(\mathrm{mDa}, \mathrm{ppm})\end{array}$ & $\begin{array}{l}\text { Measured } \\
{\left[\mathrm{M}-\mathrm{H}+\mathrm{C}_{2} \mathrm{H}_{4} \mathrm{O}_{2}\right]^{-}} \\
\text {Ion }(\mathrm{m} / \mathrm{z})\end{array}$ & $\begin{array}{l}\text { TOFMS Suggested } \\
{\left[\mathrm{M}-\mathrm{H}+\mathrm{C}_{2} \mathrm{H}_{4} \mathrm{O}_{2}\right]^{-}} \\
\text {Ion Formula }\end{array}$ & $\begin{array}{c}\text { Error } \\
(\mathrm{mDa}, \mathrm{ppm})\end{array}$ & $\begin{array}{l}\text { Proposed } \\
\text { Structure }^{\mathrm{a}}\end{array}$ \\
\hline $3.68^{b}$ & 194.0310 & $\mathrm{C}_{5} \mathrm{H}_{8} \mathrm{NO}_{7}^{-}$ & $0.9,4.6$ & $\mathrm{c}$ & & & \\
\hline $4.52^{\mathrm{b}}$ & 239.0137 & $\mathrm{C}_{5} \mathrm{H}_{7} \mathrm{~N}_{2} \mathrm{O}_{9}^{-}$ & $-1.5,-6.3$ & & & & \\
\hline $5.09^{d}$ & 304.9946 & $\mathrm{C}_{5} \mathrm{H}_{9} \mathrm{~N}_{2} \mathrm{O}_{11} \mathrm{~S}^{-}$ & $1.9,6.2$ & & & & \\
\hline $5.24^{\mathrm{b}}$ & 239.0152 & $\mathrm{C}_{5} \mathrm{H}_{7} \mathrm{~N}_{2} \mathrm{O}_{9}^{-}$ & $0.0,0.0$ & & & & \\
\hline $5.43^{\mathrm{d}}$ & 304.9944 & $\mathrm{C}_{5} \mathrm{H}_{9} \mathrm{~N}_{2} \mathrm{O}_{11} \mathrm{~S}^{-}$ & $1.7,5.6$ & & & & \\
\hline 6.07 & 225.0350 & $\mathrm{C}_{5} \mathrm{H}_{9} \mathrm{~N}_{2} \mathrm{O}_{8}^{-}$ & $-0.9,-4.0$ & & & & \\
\hline 6.12 & 225.0342 & $\mathrm{C}_{5} \mathrm{H}_{9} \mathrm{~N}_{2} \mathrm{O}_{8}^{-}$ & $-1.7,-7.6$ & & & & \\
\hline 6.60 & 225.0375 & $\mathrm{C}_{5} \mathrm{H}_{9} \mathrm{~N}_{2} \mathrm{O}_{8}^{-}$ & $1.6,7.1$ & 285.0676 & $\mathrm{C}_{7} \mathrm{H}_{13} \mathrm{~N}_{2} \mathrm{O}_{10}^{-}$ & $0.6,2.1$ & \\
\hline $7.75^{\mathrm{d}}$ & 349.9775 & $\mathrm{C}_{5} \mathrm{H}_{8} \mathrm{~N}_{3} \mathrm{O}_{13} \mathrm{~S}^{-}$ & $-0.3,-0.9$ & & & & \\
\hline $7.85^{\mathrm{d}}$ & 349.9764 & $\mathrm{C}_{5} \mathrm{H}_{8} \mathrm{~N}_{3} \mathrm{O}_{13} \mathrm{~S}^{-}$ & $0.2,0.6$ & & & & \\
\hline $8.00^{\mathrm{d}}$ & 349.9784 & $\mathrm{C}_{5} \mathrm{H}_{8} \mathrm{~N}_{3} \mathrm{O}_{13} \mathrm{~S}^{-}$ & $-0.4,-1.1$ & & & & \\
\hline $8.48^{\mathrm{d}}$ & 466.0268 & $\mathrm{C}_{10} \mathrm{H}_{16} \mathrm{~N}_{3} \mathrm{O}_{16} \mathrm{~S}^{-}$ & $1.7,3.6$ & & & & \\
\hline $8.54^{\mathrm{d}}$ & 466.0264 & $\mathrm{C}_{10} \mathrm{H}_{16} \mathrm{~N}_{3} \mathrm{O}_{16} \mathrm{~S}^{-}$ & $1.3,2.8$ & & & & \\
\hline $8.72^{\mathrm{d}}$ & 466.0237 & $\mathrm{C}_{10} \mathrm{H}_{16} \mathrm{~N}_{3} \mathrm{O}_{16} \mathrm{~S}^{-}$ & $-1.4,-3.0$ & & & & \\
\hline $8.76^{\mathrm{e}}$ & 270.0199 & $\mathrm{C}_{5} \mathrm{H}_{8} \mathrm{~N}_{3} \mathrm{O}_{10}^{-}$ & $-1.1,-4.1$ & 330.0393 & $\mathrm{C}_{7} \mathrm{H}_{12} \mathrm{~N}_{3} \mathrm{O}_{12}^{-}$ & $-2.8,-8.5$ & \\
\hline $8.81^{\mathrm{d}}$ & 466.0237 & $\mathrm{C}_{10} \mathrm{H}_{16} \mathrm{~N}_{3} \mathrm{O}_{16} \mathrm{~S}^{-}$ & $-1.4,-3.0$ & & & & \\
\hline $8.85^{\mathrm{e}}$ & 270.0204 & $\mathrm{C}_{5} \mathrm{H}_{8} \mathrm{~N}_{3} \mathrm{O}_{10}^{-}$ & $-0.6,-2.2$ & 330.0379 & $\mathrm{C}_{7} \mathrm{H}_{12} \mathrm{~N}_{3} \mathrm{O}_{12}^{-}$ & $-4.2,-12.7$ & \\
\hline 9.15 & 370.0734 & $\mathrm{C}_{10} \mathrm{H}_{16} \mathrm{~N}_{3} \mathrm{O}_{12}^{-}$ & $0.9,2.4$ & 430.0940 & $\mathrm{C}_{12} \mathrm{H}_{20} \mathrm{~N}_{3} \mathrm{O}_{14}^{-}$ & $-0.5,-1.2$ & \\
\hline 9.19 & 386.0678 & $\mathrm{C}_{10} \mathrm{H}_{16} \mathrm{~N}_{3} \mathrm{O}_{13}^{-}$ & $-0.5,-1.3$ & 446.0888 & $\mathrm{C}_{12} \mathrm{H}_{20} \mathrm{~N}_{3} \mathrm{O}_{15}^{-}$ & $-0.6,-1.3$ & \\
\hline 9.24 & 370.0732 & $\mathrm{C}_{10} \mathrm{H}_{16} \mathrm{~N}_{3} \mathrm{O}_{12}^{-}$ & $-0.2,-0.5$ & 430.0937 & $\mathrm{C}_{12} \mathrm{H}_{20} \mathrm{~N}_{3} \mathrm{O}_{14}^{-}$ & $-0.8,-1.9$ & \\
\hline 9.25 & 386.0683 & $\mathrm{C}_{10} \mathrm{H}_{16} \mathrm{~N}_{3} \mathrm{O}_{13}^{-}$ & $-0.2,-0.5$ & 446.0893 & $\mathrm{C}_{12} \mathrm{H}_{20} \mathrm{~N}_{3} \mathrm{O}_{15}^{-}$ & $-0.1,-0.2$ & \\
\hline 9.37 & 449.0637 & $\mathrm{C}_{10} \mathrm{H}_{17} \mathrm{~N}_{4} \mathrm{O}_{16}^{-}$ & $-0.3,-0.7$ & 509.0854 & $\mathrm{C}_{12} \mathrm{H}_{21} \mathrm{~N}_{4} \mathrm{O}_{18}^{-}$ & $0.3,0.6$ & \\
\hline 9.41 & 386.0684 & $\mathrm{C}_{10} \mathrm{H}_{16} \mathrm{~N}_{3} \mathrm{O}_{13}^{-}$ & $0.1,0.3$ & 446.0903 & $\mathrm{C}_{12} \mathrm{H}_{20} \mathrm{~N}_{3} \mathrm{O}_{15}^{-}$ & $0.9,2.0$ & \\
\hline 9.45 & 449.0653 & $\mathrm{C}_{10} \mathrm{H}_{17} \mathrm{~N}_{4} \mathrm{O}_{16}^{-}$ & $1.3,2.9$ & 509.0853 & $\mathrm{C}_{12} \mathrm{H}_{21} \mathrm{~N}_{4} \mathrm{O}_{18}^{-}$ & $0.2,0.4$ & \\
\hline $9.90^{\mathrm{f}}$ & 494.0537 & $\mathrm{C}_{10} \mathrm{H}_{16} \mathrm{~N}_{5} \mathrm{O}_{18}^{-}$ & $4.7,9.5$ & 554.0669 & $\mathrm{C}_{12} \mathrm{H}_{20} \mathrm{~N}_{5} \mathrm{O}_{20}^{-}$ & $-3.3,-6.0$ & \\
\hline $9.98^{f}$ & 494.0518 & $\mathrm{C}_{10} \mathrm{H}_{16} \mathrm{~N}_{5} \mathrm{O}_{18}^{-}$ & $2.8,5.7$ & 554.0676 & $\mathrm{C}_{12} \mathrm{H}_{20} \mathrm{~N}_{5} \mathrm{O}_{20}^{-}$ & $-2.6,-4.7$ & \\
\hline
\end{tabular}

a Structural isomers containing nitrate, sulfate, or hyroxyl groups at other positions are likely; for simplicity, only one isomer is shown.

$\mathrm{b}$ These compounds appear to be very minor SOA products due to very small chromatographic peak areas, confirming that the further oxidation of the nitrooxycarbonyl and hydroxycarbonyl first-generation gas-phase products do not yield significant quantities of SOA.

${ }^{c}$ A blank cell indicates that the detected SOA product had no observable acetic acid adduct ion (i.e. $\left[\mathrm{M}-\mathrm{H}+\mathrm{C}_{2} \mathrm{H}_{4} \mathrm{O}_{2}\right]^{-}$).

$\mathrm{d}$ These organosulfate SOA products were observed only in experiments employing either $\left(\mathrm{NH}_{4}\right)_{2} \mathrm{SO}_{4}\left(\mathrm{i} . \mathrm{e}\right.$. neutral) or $\mathrm{MgSO}_{4}+\mathrm{H}_{2} \mathrm{SO}_{4}$ (i.e. acidic) seed aerosol. These organosulfate SOA products were also observed in the excess isoprene experiments.

${ }^{\mathrm{e}}$ In addition to the acetic acid adduct ion, these compounds also had a significant adduct ion at $\left[\mathrm{M}-\mathrm{H}+\mathrm{HNO}_{3}\right]^{-}(\mathrm{m} / z, 333)$, indicating that these compounds are likely not very stable due to the fragmentation of one of the $\mathrm{NO}_{3}$ groups during the MS analysis.

$\mathrm{f}$ These compounds were only weakly detected in the excess isoprene experiments.

attack is shown. The nitrooxyalkyl radicals then react with $\mathrm{O}_{2}$ to form $\mathrm{RO}_{2}$ radicals, which react further with $\mathrm{HO}_{2}, \mathrm{RO}_{2}$, or $\mathrm{NO}_{3}$ radicals under the experimental conditions in this study. The reaction of $\mathrm{RO}_{2}$ radicals and $\mathrm{HO}_{2}$ radicals leads to the formation of $\mathrm{C}_{5}$-nitrooxyhydroperoxide $(\mathrm{m} / z$ 248). The reaction of two $\mathrm{RO}_{2}$ radicals (self reaction or cross reaction) has three different possible channels:

$$
\begin{aligned}
\mathrm{RO}_{2}+\mathrm{RO}_{2} & \rightarrow 2 \mathrm{RO}+\mathrm{O}_{2} \\
& \rightarrow \mathrm{ROH}+\mathrm{RCHO}+\mathrm{O}_{2} \\
& \rightarrow \mathrm{ROOR}+\mathrm{O}_{2}
\end{aligned}
$$

The second channel results in the formation of $\mathrm{C}_{5}$ nitrooxycarbonyl $(\mathrm{m} / \mathrm{z}, 230)$ and $\mathrm{C}_{5}$-hydroxynitrate $(\mathrm{m} / \mathrm{z}$ 232). According to channel (5b), these two products should be formed with a 1:1 ratio; however, $\mathrm{C}_{5}$-nitrooxycarbonyl can also be formed from alkoxy radicals (alkoxy radicals formed through $\mathrm{RO}_{2}+\mathrm{RO}_{2}$ reaction or $\mathrm{RO}_{2}+\mathrm{NO}_{3}$ reaction). In Fig. 6, $49.8 \mathrm{ppb}$ of $\mathrm{C}_{5}$-nitrooxycarbonyl and $26.1 \mathrm{ppb}$ of $\mathrm{C}_{5}$-hydroxynitrate are formed after the addition of the first pulse of $\mathrm{N}_{2} \mathrm{O}_{5}$, indicating $\sim 24 \mathrm{ppb}$ of $\mathrm{C}_{5}$-nitrooxycarbonyl is formed from the reaction of alkoxy radicals. The branching ratios for the reaction of small peroxy radicals have been investigated in previous studies. It is found that the branching ratio for channel (5a) for methylperoxy and ethylperoxy radicals is $\sim 0.3-0.4$ and $\sim 0.6$, respectively (Lightfoot et al., 1992; Wallington et al., 1992; Tyndall et al., 1998). It is 
Table 3. Peroxide content of $\mathrm{SOA}$ formed by $\mathrm{NO}_{3}$ oxidation of isoprene.

\begin{tabular}{|c|c|c|c|c|c|c|c|}
\hline $\begin{array}{l}\text { Experiment } \\
\text { Date }\end{array}$ & $\begin{array}{l}\text { Seeded }^{\mathrm{a}} / \\
\text { Nucleation }\end{array}$ & $\begin{array}{l}\text { [Isoprene] } \\
\text { (ppb) }\end{array}$ & $\begin{array}{l}{\left[\mathrm{N}_{2} \mathrm{O}_{5}\right]} \\
(\mathrm{ppm})\end{array}$ & $\begin{array}{l}\text { SOA Volume } \\
\text { Growth Observed }^{\mathrm{b}} \\
\left(\mu \mathrm{m}^{3} / \mathrm{cm}^{3}\right)\end{array}$ & $\begin{array}{l}\text { Total SOA } \\
\text { Mass Concentration } \\
\left(\mu \mathrm{g} / \mathrm{m}^{3}\right)\end{array}$ & $\begin{array}{l}\text { Peroxide Aerosol } \\
\text { Mass Concentration } \\
\left(\mu \mathrm{g} / \mathrm{m}^{3}\right)\end{array}$ & $\begin{array}{l}\text { Contriubtion of } \\
\text { Peroxides to the SOA Mass } \\
\text { Concentration Observed }(\%)\end{array}$ \\
\hline $8 / 22 / 07$ & AS & 200 & 1 & 102 & 145 & 46 & 32 \\
\hline 8/30/07 & AMS & 200 & 1 & 123 & 174 & 40 & 23 \\
\hline $10 / 22 / 07^{\mathrm{d}}$ & AS & 1200 & 0.7 & 70 & 100 & b.d.l.e & f \\
\hline $10 / 23 / 07$ & nucleation & 200 & 1 & 125 & 177 & 31 & 17 \\
\hline 10/24/07 & AS & 200 & 1 & 111 & 158 & 47 & 30 \\
\hline $10 / 27 / 07^{\mathrm{g}}$ & AS & 300 & 1 & 110 & 156 & 47 & 30 \\
\hline
\end{tabular}

a $\mathrm{AS}=$ ammonium sulfate seed, $\mathrm{AMS}=$ acidified magnesium sulfate seed.

$\mathrm{b}$ Averaged over the course of filter sampling.

c Assuming a SOA density of $1.42 \mathrm{~g} / \mathrm{cm}^{3}$. This was based on DMA and Q-AMS measurements.

$\mathrm{d}$ Excess isoprene experiment.

e Below detection limits.

${ }^{\mathrm{f}}$ No observable contribution of organic peroxides to the SOA mass concentration.

$\mathrm{g}$ Slow injection of isoprene in this experiment to enhance the $\mathrm{RO}_{2}+\mathrm{NO}_{3}$ reaction pathway.

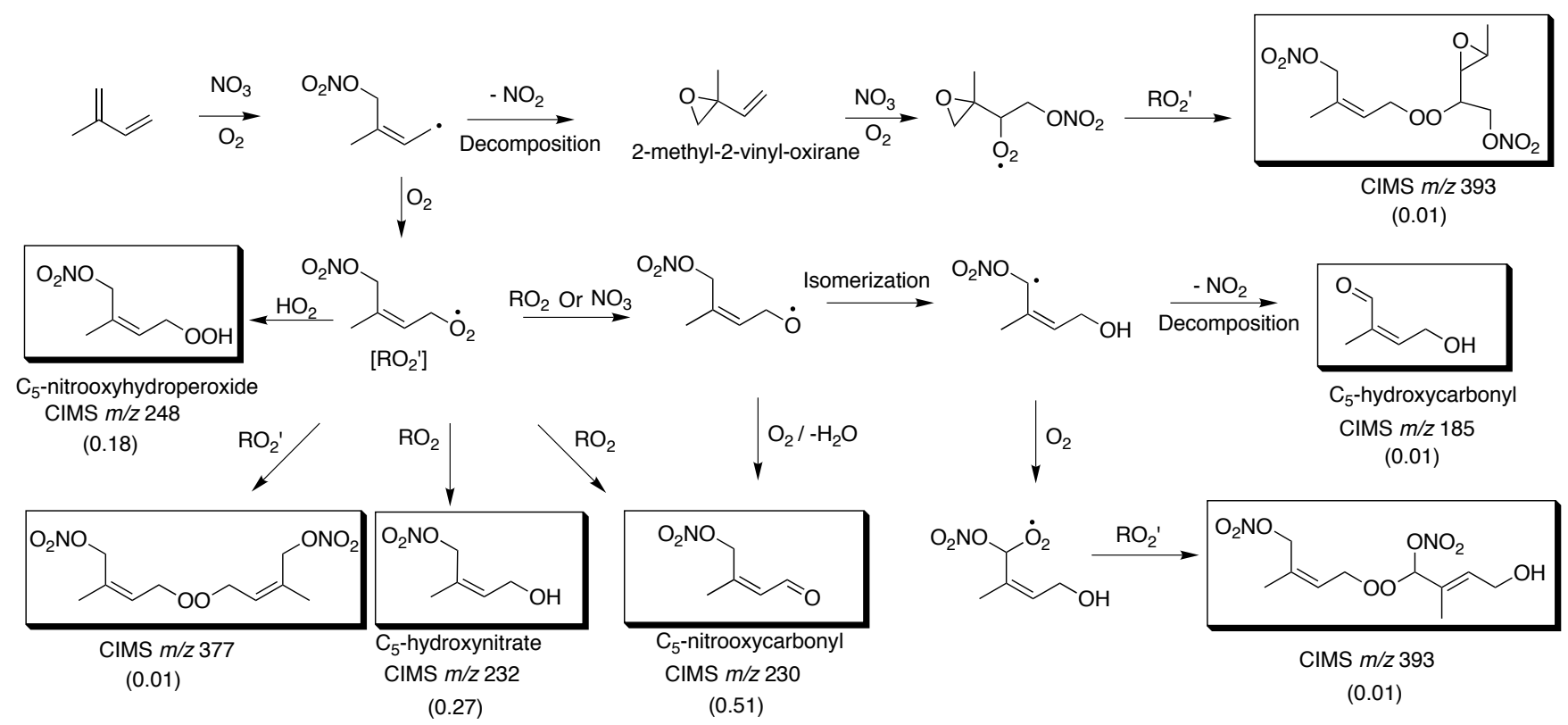

Fig. 11. Proposed mechanisms for the formation of various gas-phase intermediate product ions observed by CIMS. Multiple structural isomers are possible. In this figure, $\mathrm{RO}_{2}^{\prime}$ refers to the isoprene peroxy radical (nitrooxyperoxy radical), $\mathrm{RO}_{2}$ refer to a generic peroxy radical. The numbers in the parentheses refer to the molar yields of the products. It is noted that the sensitivity for $m / z 393$ is not calculated; instead, it is assumed that the sensitivity (and hence the sum of the molar yields of the two isomers shown, since $\mathrm{m} / z 377$ and $\mathrm{m} / z 393$ are formed with the same concentration) to be the same as that for $m / z 377$.

likely that the isoprene peroxy radicals react via this pathway to form alkoxy radicals and contribute to the "extra" $24 \mathrm{ppb}$ of $\mathrm{C}_{5}$-nitrooxycarbonyl. This observation is indicative that most $\mathrm{RO}_{2}$ radicals react with other $\mathrm{RO}_{2}$ radicals instead with $\mathrm{NO}_{3}$ or $\mathrm{HO}_{2}$ radicals.

Other than $\mathrm{C}_{5}$-nitrooxycarbonyl, $\mathrm{C}_{5}$-hydroxynitrate, and $\mathrm{C}_{5}$-nitrooxyhydroperoxide, three other minor products $(\mathrm{m} / \mathrm{z}$ 185,377 and 393 ions) are also observed as intermediate products. The proposed mechanisms for the formation of these gas-phase products are also shown in Fig. 11. Although channel $(5 \mathrm{c})$ in the $\mathrm{RO}_{2}+\mathrm{RO}_{2}$ reaction is found to be minor for small peroxy radicals such as methylperoxy and ethylperoxy radicals (Kan et al., 1980; Niki et al., 1981, 1982; Wallington et al., 1989; Tyndall et al., 1998; Tyndall et al., 2001), the product ion at $m / z 377$ could be the corresponding ROOR product formed from the self reaction of isoprene peroxy radicals. The product ion at $\mathrm{m} / \mathrm{z} 185$ likely corresponds to the $\mathrm{C}_{5}$-hydroxycarbonyl. It has been observed 


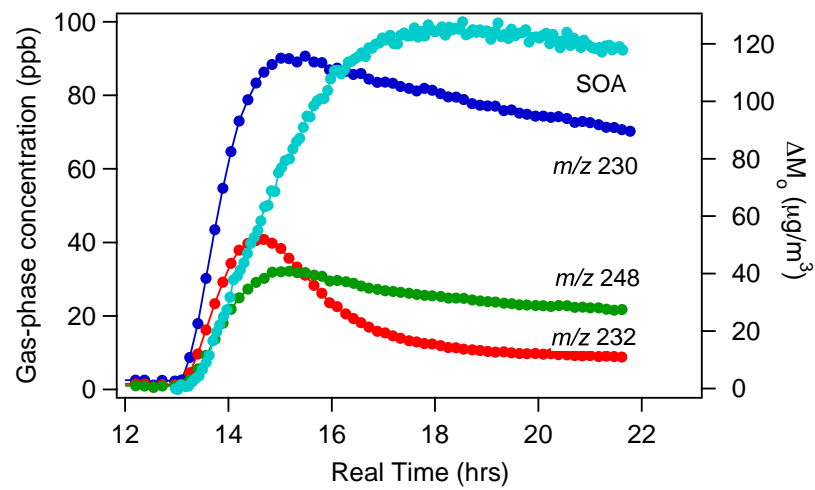

Fig. 12. Time profiles of the major gas-phase products $(\mathrm{m} / \mathrm{z} 230$, 232, and 248) and the corresponding aerosol growth from the slow $\mathrm{N}_{2} \mathrm{O}_{5}$ injection experiment. Note that this experiment has a higher initial isoprene concentration $(\sim 200 \mathrm{ppb})$ compared to the one shown in Fig. 4.

in previous studies and it likely arises from the isomerization of nitrooxyalkoxy radicals through a 6-member transition state to form a hydroxynitrooxy alkyl radical, which then decomposes to form $\mathrm{NO}_{2}$ and $\mathrm{C}_{5}$-hydroxycarbonyl (Kwok et al., 1996). Such isomerization has also been proposed to occur in the photooxidation of isoprene (Paulson and Seinfeld, 1992; Carter and Atkinson, 1996; Dibble, 2002). It is possible that the hydroxynitrooxy alkyl radical formed proceeds to react with $\mathrm{O}_{2}$ to form a peroxy radical, which then reacts with the isoprene peroxy radical to form the product ion at $m / z$ 393. The product ion at $m / z 393$ shows a slower rate of formation (Fig. 6) compared to other product ions suggesting that it might also be formed from the further oxidation of a first-generation product. 2-methyl-2-vinyl-oxirane has been observed from isoprene- $\mathrm{NO}_{3}$ reaction in previous studies at 20 mbar in helium (Berndt and Böge, 1997) and 20 Torr in argon (Skov et al., 1994), respectively. When operated in positive mode with $\mathrm{H}_{3} \mathrm{O}^{+}$as the reagent ion (products are observed at $m / z=\mathrm{MW}+1$ ), CIMS shows a protonated molecule at $m / z$ 85. Although the epoxide yield is found to be $<1 \%$ of the total reacted isoprene at atmospheric pressure (Skov et al., 1994), the signal at $m / z 85$ can arise in part from the epoxide. The further oxidation of the epoxide results in the formation of an epoxide peroxy radical, which can react with the isoprene peroxy radical to form the peroxide at $m / z 393$. It is noted that a product ion at $m / z 246$ is detected in CIMS, which could arise from the corresponding carbonyl product formed from the reactions of two epoxide peroxy radicals, or from the fragmentation of the epoxide alkoxy radicals. Unlike $m / z 393$, which decays after the addition of the last pulse of $\mathrm{N}_{2} \mathrm{O}_{5}, \mathrm{~m} / z 246$ stays relatively constant suggesting that it is not being further oxidized by $\mathrm{NO}_{3}$ radicals. To examine further the possibility of peroxide formation $(\mathrm{m} / z 377$ and 393) in the gas phase, an experiment is conducted using 1,3-butadiene as the parent hydrocarbon. The analogous

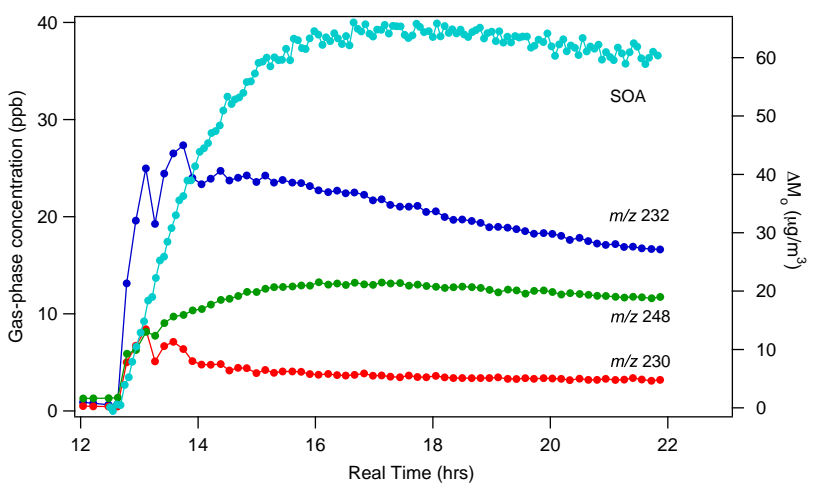

Fig. 13. Time profiles of the major gas-phase products $(\mathrm{m} / \mathrm{z} 230$, 232 , and 248) and the corresponding aerosol growth from the slow isoprene injection experiment. Note that this experiment has a higher initial isoprene concentration $(\sim 200 \mathrm{ppb})$ compared to the one shown in Fig. 4.

product ions for the 1,3-butadiene system, i.e. $\mathrm{m} / \mathrm{z} 349$ and 365 , are observed in CIMS, providing further indication that the formation of ROOR products from two $\mathrm{RO}_{2}$ radicals is occurring in the gas phase. Further details of the gas-phase chemistry of isoprene and 1,3-butadiene will be forthcoming in a future manuscript.

\subsection{Effect of peroxy radical chemistry on SOA yield}

The SOA yield ranges from $4.3 \%$ to $23.8 \%$ for an initial isoprene concentration of 18.4 to $101.6 \mathrm{ppb}$ in the typical yield experiments. While the SOA yield from the slow $\mathrm{N}_{2} \mathrm{O}_{5}$ injection experiment is roughly the same as that in the typical yield experiments, the SOA yield from the slow isoprene injection experiment is lower (Fig. 3). In both cases, $\sim 40 \mathrm{ppb}$ of isoprene is consumed, the main difference being the relative importance of $\mathrm{RO}_{2}+\mathrm{RO}_{2}$ reaction versus $\mathrm{RO}_{2}+\mathrm{NO}_{3}$ reaction in each system. In the slow $\mathrm{N}_{2} \mathrm{O}_{5}$ injection experiment, a relatively small amount of $\mathrm{NO}_{3}$ is available in the chamber. Once $\mathrm{RO}_{2}$ radicals are formed, it is expected that they would react primarily with other $\mathrm{RO}_{2}$ radicals instead of $\mathrm{NO}_{3}$ radicals owing to the presence of a relatively higher isoprene concentration in the chamber. On the other hand, the slow isoprene injection experiment favors $\mathrm{RO}_{2}+\mathrm{NO}_{3}$ reaction owing to the presence of excess $\mathrm{N}_{2} \mathrm{O}_{5}$ in the chamber. Thus the higher SOA yield observed in the slow $\mathrm{N}_{2} \mathrm{O}_{5}$ injection experiment suggests the products formed via $\mathrm{RO}_{2}+\mathrm{RO}_{2}$ reaction partition more readily into the aerosol phase, or the $\mathrm{RO}_{2}+\mathrm{RO}_{2}$ reaction forms products that further react and contribute significantly to aerosol growth. The fact that the SOA yield from the slow $\mathrm{N}_{2} \mathrm{O}_{5}$ injection experiment is roughly the same as in the typical yield experiments implies that $\mathrm{RO}_{2}+\mathrm{RO}_{2}$ reaction dominates in typical yield experiments.

The time profile for the three major first-generation gas phase products and SOA growth from the slow $\mathrm{N}_{2} \mathrm{O}_{5}$ injection experiment and slow isoprene injection experiment are 
shown in Figs. 12 and 13, respectively. It is noted that this pair of experiments has a higher initial isoprene concentration ( $\sim 200 \mathrm{ppb}$ ) compared to the pair of experiments shown in Fig. 4. In both cases, once the first-generation products are formed they can react further with $\mathrm{NO}_{3}$ radicals, making it difficult to estimate the formation yields of these products based on the measured concentrations. The extent to which these products react further is expected to be higher in the slow isoprene injection experiment owing to the presence of excess $\mathrm{NO}_{3}$ in chamber; this is consistent with the relatively lower concentrations of first-generation products observed. As mentioned before, it is possible that the CIMS signal at the observed $\mathrm{m} / \mathrm{z}$ comprises isomers formed from the $\mathrm{NO}_{3}$ attack at positions other than the $\mathrm{C} 1$ carbon. Such isomers have slightly different structures but they could exhibit a very different reaction rate towards $\mathrm{NO}_{3}$ radicals. For instance, studies have shown that the reaction rates of $\mathrm{NO}_{3}$ radicals with unsaturated alcohols and unsaturated carbonyl compounds can vary by several orders of magnitude depending on the position of the substituted methyl group (Noda et al., 2002; Canosa-Mas et al., 2005). It is possible that the minor products formed from $\mathrm{NO}_{3}$ attack at other positions react much slower with $\mathrm{NO}_{3}$ radicals, hence the concentrations of the observed product ions do not decay to zero towards the end of the experiment. At the end of the experiment, about $8 \mathrm{ppb}$ and $3 \mathrm{ppb}$ of $\mathrm{C}_{5}$-hydroxynitrate is left in the slow $\mathrm{N}_{2} \mathrm{O}_{5}$ injection experiment and slow isoprene injection experiment, respectively. Assuming the amount of reactive isomers and unreactive (or relatively slow reacting) isomers are formed in the same ratio in the slow $\mathrm{N}_{2} \mathrm{O}_{5}$ injection experiment and the slow isoprene injection experiment, we can deduce that a relatively higher concentration of reactive $\mathrm{C}_{5}$-hydroxynitrate (as well as the two other first-generation products) is formed in the slow $\mathrm{N}_{2} \mathrm{O}_{5}$ injection experiment. This is consistent with the larger extent of $\mathrm{RO}_{2}+\mathrm{RO}_{2}$ reaction (which forms $\mathrm{C}_{5}$-hydroxynitrate) and the higher SOA yield observed in the slow $\mathrm{N}_{2} \mathrm{O}_{5}$ injection experiment, as it appears that $\mathrm{C}_{5}$ hydroxynitrate is an effective SOA precursor (Fig. 6).

\subsection{Growth curves: multiple steps in SOA formation}

By examining the time-dependent growth curves (organic aerosol, $\Delta M_{o}$, as a function of hydrocarbon reacted, $\Delta \mathrm{HC}$ ) we can gain insights into the general mechanisms of SOA formation ( $\mathrm{Ng}$ et al., 2006, 2007a,b). Figure 4 shows the time-dependent growth curves for the slow $\mathrm{N}_{2} \mathrm{O}_{5}$ injection experiment and the slow isoprene injection experiment, respectively. For the slow $\mathrm{N}_{2} \mathrm{O}_{5}$ injection experiment, the initial aerosol growth likely arises from the condensation of first-generation products as the presence of excess isoprene in the chamber suppresses their further oxidation. If higher generation products do contribute to SOA formation, they would have to be formed at relatively fast rates. After isoprene is consumed, aerosol mass continue to increase and results in a "hook" in the growth curve. This indicates that secondary products (or higher generation products) also contribute significantly to SOA formation. The same observation can be made if we examine the reaction profile of a typical yield experiment (Fig. 2): there is further SOA growth after all isoprene is reacted away, indicating that the further oxidation of first generation products are contributing to SOA formed. These observations are consistent with the fact that the decay of first-generation products observed in CIMS (especially the $m / z 232$ and $m / z 377$ ions) is strongly anticorrelated with further SOA growth (Fig. 6). On the other hand, the slow isoprene injection experiment does not allow us to differentiate the contribution of first- and second-generation products to SOA formation. With the presence of excess $\mathrm{NO}_{3}$ radicals in the chamber, the first-generation products formed in the slow isoprene injection experiment would be further oxidized once they are formed. The SOA growth observed throughout this experiment is from the partitioning of these highly oxidized and nonvolatile products. Hence, at the beginning of the experiment, for the same amount of $\triangle \mathrm{HC}$, the amount of SOA formed in this experiment is higher than that in the slow $\mathrm{N}_{2} \mathrm{O}_{5}$ injection experiment, in which the aerosol growth is probably from the condensation of relatively more volatile first-generation products. Both the AMS data and filter sample data (Figs. 8, 9, and 10) show a very similar composition for the final SOA formed in slow $\mathrm{N}_{2} \mathrm{O}_{5}$ injection experiment and the slow isoprene injection experiment, suggesting a common SOA forming channel. Based on the previous discussion on the effect of peroxy radical chemistry on SOA yields, it is likely that the $\mathrm{RO}_{2}+\mathrm{RO}_{2}$ reaction is the SOA-forming channel in both cases; such a reaction occurs to a large extent in the slow $\mathrm{N}_{2} \mathrm{O}_{5}$ injection experiments and results in the formation of more SOA.

\subsection{Proposed mechanisms of SOA formation}

The combination of CIMS gas-phase data and elemental SOA composition data provides substantial insights into the mechanisms of SOA formation. Shown in Figs. 14-17 are the proposed SOA formation mechanisms from the further oxidation of the various gas-phase products measured by CIMS. The compounds in the boxes are the SOA products detected by UPLC/(-)ESI-TOFMS. Owing to multiple chromatographic peaks observed in the UPLC/(-)ESI-TOFMS extracted ion chromatograms (EICs) for the negative ions of the proposed SOA products, structural isomers are likely; however, for simplicity we show only one possible isomer for each product formed from a particular reaction pathway. Many of the SOA products detected are formed from the further oxidation of first- or higher-generation products, which is consistent with the observation of continual SOA growth after the complete consumption of isoprene (hence a "hook" in the growth curve). With the large number of nitratesubstituted compounds detected by UPLC/(-)ESI-TOFMS technique, it is also not surprising that AMS shows strong signals at $m / z 30\left(\mathrm{NO}^{+}\right)$and $m / z 46\left(\mathrm{NO}_{2}^{+}\right)$. 


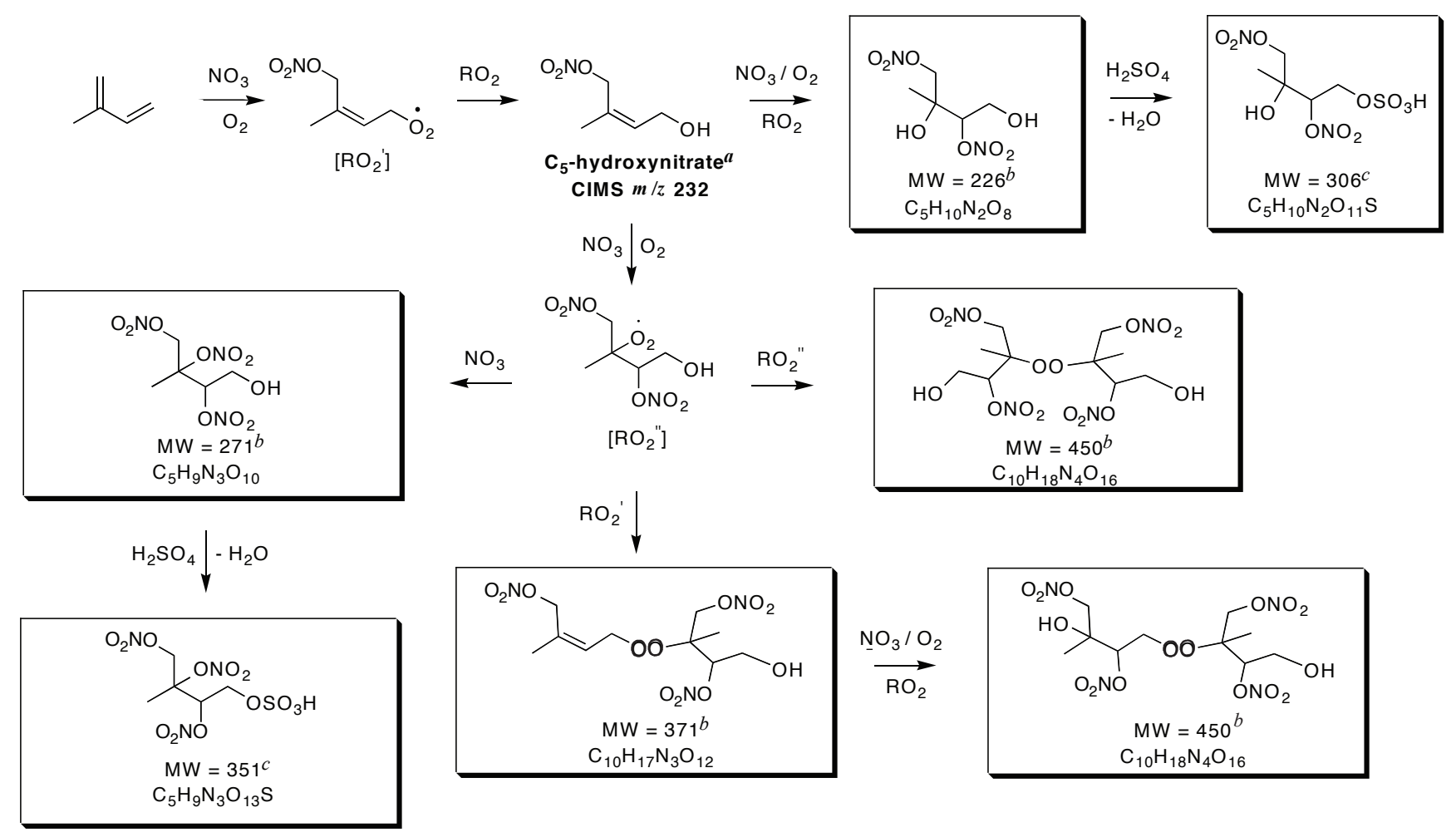

Fig. 14. Proposed mechanism for SOA formation from the formation and decay of the $\mathrm{C}_{5}$-hydroxynitrate gas-phase product formed from the isoprene $+\mathrm{NO}_{3}$ reaction. Boxes indicate UPLC/(-)ESI-TOFMS detected SOA products; molecular formulas were confirmed by the accurate mass data provided by the UPLC/(-)ESI-TOFMS. Multiple structural isomers are possible, consistent with the multiple chromatographic peaks observed in the extracted ion chromatograms; however, only one structural isomer is shown for simplicity. ${ }^{\mathrm{a}}$ This first-generation gas-phase product was previously observed by Jay and Stieglitz (1989), Skov et al. (1992), Kwok et al. (1996), and Berndt and Böge (1997); this gas-phase product was detected as the $\left[\mathrm{M}+\mathrm{CF}_{3} \mathrm{O}\right]^{-}$ion by the CIMS instrument. ${ }^{\mathrm{b}}$ These particle-phase compounds were detected as both their $[\mathrm{M}-\mathrm{H}]^{-}$and $\left[\mathrm{M}-\mathrm{H}+\mathrm{C}_{2} \mathrm{H}_{4} \mathrm{O}_{2}\right]^{-}$ions; the acetic acid adduct $\left(\left[\mathrm{M}-\mathrm{H}+\mathrm{C}_{2} \mathrm{H}_{4} \mathrm{O}_{2}\right]^{-}\right)$ion was, in most cases, the molecular ion (i.e. dominant ion). ${ }^{c}$ These organosulfate compounds were detected as their $[\mathrm{M}-\mathrm{H}]^{-}$ions and were observed only in ammonium sulfate and acidified magnesium sulfate seeded experiments.

Shown in Figs. 14 and 15 are the proposed SOA formation pathways from the further oxidation of the $m / z 232$ (i.e. $\mathrm{C}_{5}$ hydroxynitrate) and 377 gas-phase product ions (as detected by CIMS). The decay of these two products has been found to be strongly correlated with aerosol growth (Fig. 6), which is consistent with the large number of SOA products formed from their further oxidation. The further oxidation of these two gas-phase products also yields SOA compounds of the same molecular weight (compounds of MW 371 and 450). Although $m / z 393$ is a minor gas-phase product, the further oxidation of this compound leads to formation of several SOA products (Fig. 16). As mentioned before, there are two possible formation routes for $m / z$ 393, and the further oxidation of both products is shown in Fig. 16. The further oxidation of the $m / z 393$ ion appears to yield SOA products that are specific only to this gas-phase product: these include the SOA products of MW 387 and 467.
Figure 17 shows the proposed SOA formation mechanisms from three other gas-phase products $(\mathrm{m} / \mathrm{z} 185, \mathrm{~m} / \mathrm{z}$ 230 , and $m / z$ 277); the further oxidation of these product ions leads to relatively minor SOA products. Although $\mathrm{C}_{5}$-nitrooxycarbonyl $(\mathrm{m} / \mathrm{z} 230)$ is the most abundant gasphase product detected by CIMS, its further oxidation is not well correlated with aerosol growth (Fig. 6). The further oxidation of $\mathrm{m} / z 230$ yields an SOA product at MW 240. This organic acid product is found to be quite minor when examining the peak area in its corresponding extracted ion chromatogram (EIC). It is noted that no SOA products are detected from the further oxidation of the $\mathrm{C}_{5}$ nitrooxyhydroperoxide $(\mathrm{m} / \mathrm{z} 248)$ (also a major gas-phase product); it is possible that these hydroperoxide products are not acidic enough to be detected by the UPLC/(-)ESITOFMS technique, or degrade during sample workup and/or analysis procedures. It has been shown that hydroxycarbonyl 


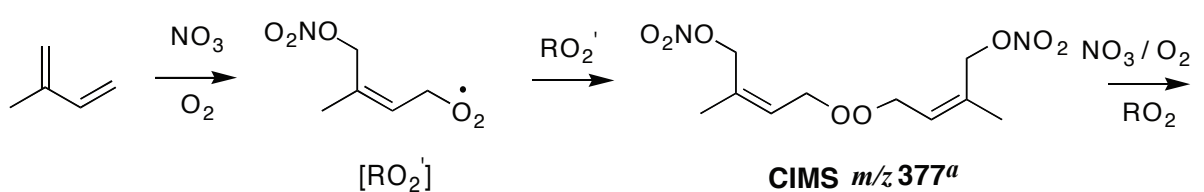

$\left[\mathrm{RO}_{2}\right]$

CIMS $m / z 377^{a}$

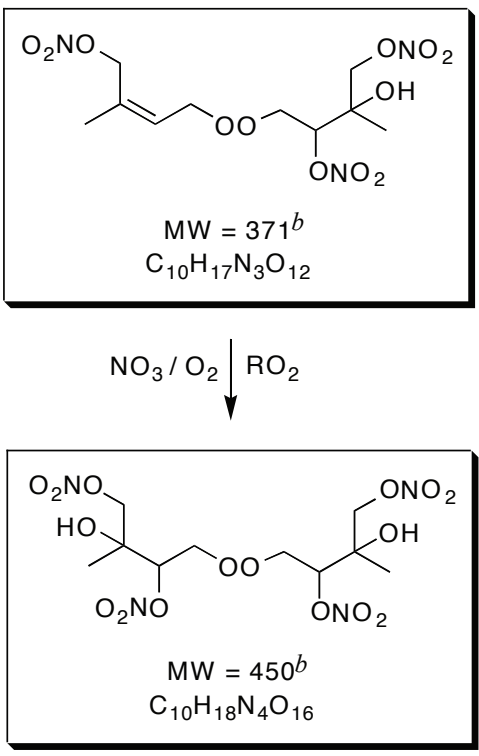

Fig. 15. Proposed mechanism for SOA formation from the formation and decay of the CIMS $m / z 377$ gas-phase product formed from the isoprene $+\mathrm{NO}_{3}$ reaction. Boxes indicate UPLC/(-)ESI-TOFMS detected SOA products; molecular formulas were confirmed by the accurate mass data provided by the UPLC/(-)ESI-TOFMS. Multiple structural isomers are possible, consistent with the multiple chromatographic peaks observed in the extracted ion chromatograms; however, only one structural isomer is shown for simplicity. ${ }^{\mathrm{a}}$ This first-generation gasphase product was detected as the $\left[\mathrm{M}+\mathrm{CF}_{3} \mathrm{O}\right]^{-}$ion by the CIMS instrument. ${ }^{\mathrm{b}}$ These particle-phase compounds were detected as both their $[\mathrm{M}-\mathrm{H}]^{-}$and $\left[\mathrm{M}-\mathrm{H}+\mathrm{C}_{2} \mathrm{H}_{4} \mathrm{O}_{2}\right]^{-}$ions; the acetic acid adduct $\left(\left[\mathrm{M}-\mathrm{H}+\mathrm{C}_{2} \mathrm{H}_{4} \mathrm{O}_{2}\right]^{-}\right)$ion was, in most cases, the molecular ion (i.e. dominant ion).

plays a key role in SOA formation from the reaction of linear alkenes with $\mathrm{NO}_{3}$ radicals (Gong et al., 2005), however, in the isoprene- $\mathrm{NO}_{3}$ system, the further oxidation of the minor gas-phase product $\mathrm{C}_{5}$-hydroxycarbonyl $(\mathrm{m} / \mathrm{z}, 185)$ leads to the formation of only one minor aerosol product at $\mathrm{MW}$ 195. Some evidence for the formation of a $\mathrm{C}_{5}$-dinitrate firstgeneration gas-phase product is indicated from the CIMS and UPLC/(-)ESI-TOFMS data. This first-generation gasphase product has been observed previously by Werner et al. (1997). The CIMS shows a weak signal at $m / z$ 277, which could be associated to the dinitrate product; we do not know, however, whether the negative ion efficiently clusters with such compounds. Further evidence for the dinitrate gas-phase product is provided by the UPLC/(-)ESITOFMS detection of an SOA product at MW 495, which could result from the further oxidation of a $\mathrm{C}_{5}$-dinitrate precursor. The precursor compound before the last oxidation step shown in this mechanism in Fig. 17 may exist in the particle phase; however, this compound is not likely to be detected by the UPLC/(-)ESI-TOFMS technique owing to the lack of acidic hydrogens from neighboring hydroxyl and/or carboxyl groups.
The SOA products highlighted in Figs. 14-17 are observed in all major experiments conducted; however, not all of these products are strongly detected in the excess isoprene experiment (Fig. 10c). With the presence of excess isoprene, further oxidations of first-generation products should be minimal and no significant SOA formation is expected. The reaction rate of isoprene and $\mathrm{NO}_{3}$ radicals is $k_{\mathrm{NO}_{3}}=7 \times 10^{-13} \mathrm{~cm}^{3}$ molecule ${ }^{-1} \mathrm{~s}^{-1}$. To our knowledge, the reaction rate of the first-generation products and $\mathrm{NO}_{3}$ radicals has not been studied. The structure of $\mathrm{m} / \mathrm{z}$ $232\left(\mathrm{C}_{5}\right.$-hydroxynitrate $)$ is similar to 3-methyl-2-buten-1-ol (MBO321), except that the $\gamma$-carbon has one nitro group and one methyl group substitution instead of two methyl group substitutions. The reaction rate coefficient of MBO321 and $\mathrm{NO}_{3}$ radicals is $k_{\mathrm{NO}_{3}}=1 \times 10^{-12} \mathrm{~cm}^{3}$ molecule $\mathrm{e}^{-1} \mathrm{~s}^{-1}$. It is found that the reaction rate with $\mathrm{NO}_{3}$ radicals increases with increasing number of methyl groups at the $\gamma$-carbon (Noda et al., 2002), which is in accordance with the stabilization theory for leaving groups discussed in Atkinson (1997) and Noda et al. (2000). With reference to this, we would expect the reaction rate of $\mathrm{C}_{5}$-hydroxynitrate and $\mathrm{NO}_{3}$ radicals to be slower than that of MBO321 due to the presence of the electron withdrawing nitro group. Hence, it is likely that the reaction rate of isoprene and $\mathrm{NO}_{3}$ radicals and $\mathrm{C}_{5}$-hydroxynitrate and $\mathrm{NO}_{3}$ radicals are roughly in the same range. The relative production rate of firstand second-generation products will then be the ratio of the 


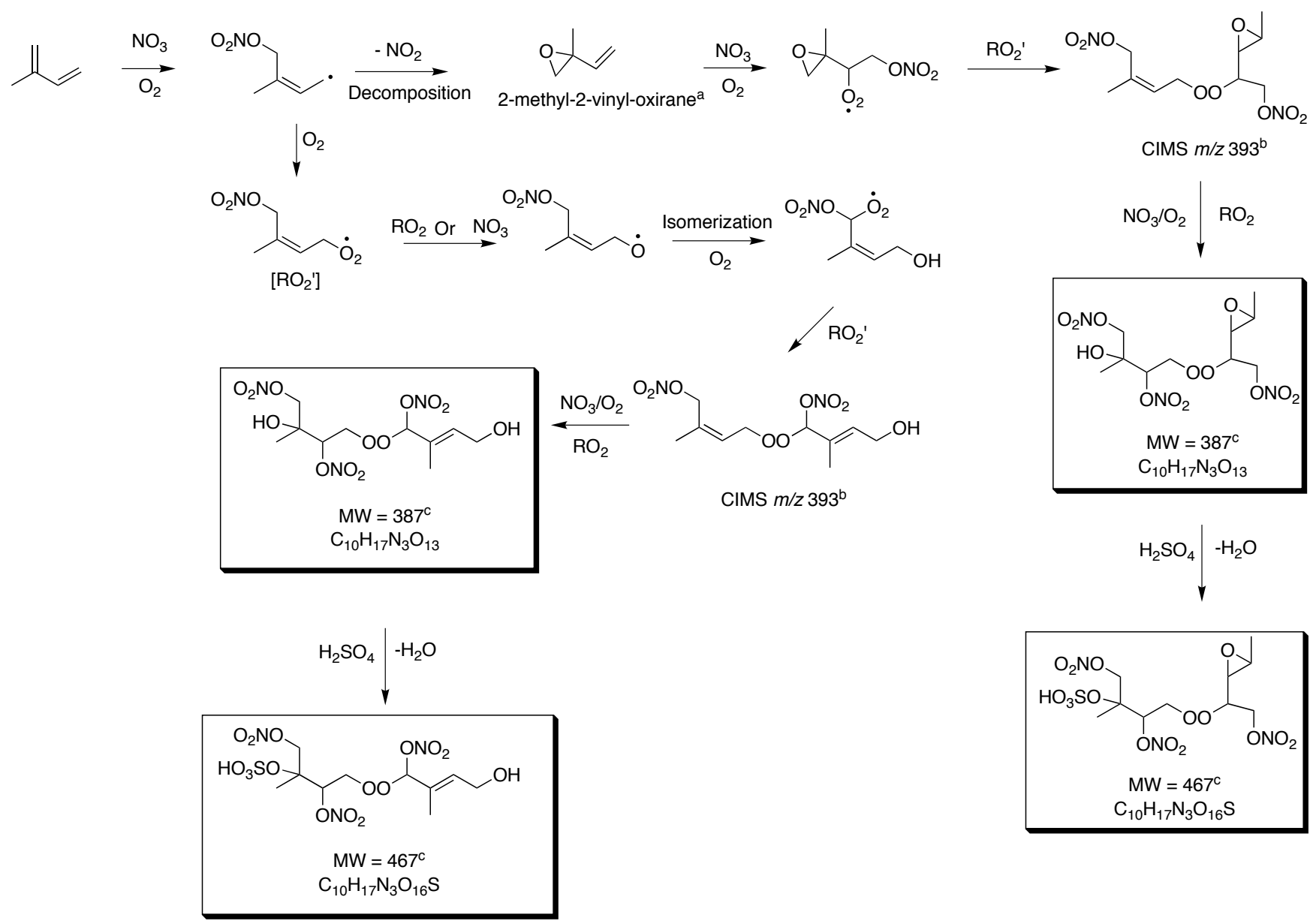

Fig. 16. Proposed mechanism for SOA formation from the formation and decay of the CIMS $\mathrm{m} / z 393$ gas-phase product formed from the isoprene $+\mathrm{NO}_{3}$ reaction. Boxes indicate UPLC/(-)ESI-TOFMS detected SOA products; molecular formulas were confirmed by the accurate mass data provided by the UPLC/(-)ESI-TOFMS. Multiple structural isomers are possible, consistent with the multiple chromatographic peaks observed in the extracted ion chromatograms; however, only one structural isomer is shown for simplicity. a This first-generation gas-phase product was detected as the $[\mathrm{M}+\mathrm{H}]^{+}$ion by the CIMS instrument; this gas-phase product was previously observed by Berndt and Böge (1997) and could also be 2-(1-methyl-vinyl)oxirane. ${ }^{b}$ This gas-phase product was detected as the $\left[\mathrm{M}+\mathrm{CF}_{3} \mathrm{O}\right]^{-}$ion. ${ }^{\mathrm{c}}$ These particle-phase compounds were detected as both their $[\mathrm{M}-\mathrm{H}]^{-}$and $\left[\mathrm{M}-\mathrm{H}+\mathrm{C}_{2} \mathrm{H}_{4} \mathrm{O}_{2}\right]^{-}$ions; the acetic acid adduct $\left(\left[\mathrm{M}-\mathrm{H}+\mathrm{C}_{2} \mathrm{H}_{4} \mathrm{O}_{2}\right]^{-}\right)$ion was, in most cases, the molecular ion (i.e. dominant ion). ${ }^{d}$ This organosulfate compound was detected as its $[\mathrm{M}-\mathrm{H}]^{-}$ion and was observed only in the ammonium sulfate and acidified magnesium sulfate seeded experiments.

concentrations of isoprene and first-generation products, and aerosol can be formed either from the condensation of relatively non-volatile first-generation products (e.g. $m / z$ 393) or higher generation products that are formed relatively fast in the gas-phase. It appears from the UPLC/(-)ESI-TOFMS data that enough $\mathrm{RO}_{2}+\mathrm{RO}_{2}$ chemistry is occurring to yield many of the products shown in Figs. 14-17. When comparing the UPLC/(-)ESI-TOFMS BPCs (Fig. 10) of all experiments, it is clear that the $m / z 430$ and $m / z 446$ are the dominant ions in the excess isoprene experiment, while $m / z 333$ is the dominant chromatographic peak in other experiments. The chromatographic peak at $\mathrm{m} / \mathrm{z} 430$ corresponds to the acetic acid cluster ion for the compound at MW 371, which can be formed from the further oxidation of CIMS $m / z 232$ and 377 ions (Figs. 14 and 15). The chromatographic peak at $m / z 446$ corresponds to the acetic acid cluster ion for the compound at MW 387, which is formed from the further oxidation of CIMS $m / z 393$ (Fig. 16). The detection of these two SOA products (MW 371 and MW 387) suggests that further oxidation of $m / z 232,377$, and 393 is occurring in the excess isoprene experiment and contributing to SOA growth. Studies have shown that $\mathrm{NO}_{3}$ uptake on organic surfaces (even to saturated organic surfaces) be quite rapid (Moise et al., 2002; Knopf et al., 2006; Rudich et al., 2007). Hence, it is also possible that CIMS $m / z 393$ (a first-generation product according to one of the formation routes) is nonvolatile enough that it partitions into the aerosol phase and its further oxidation proceeds heterogeneously. Chromatographic peaks 

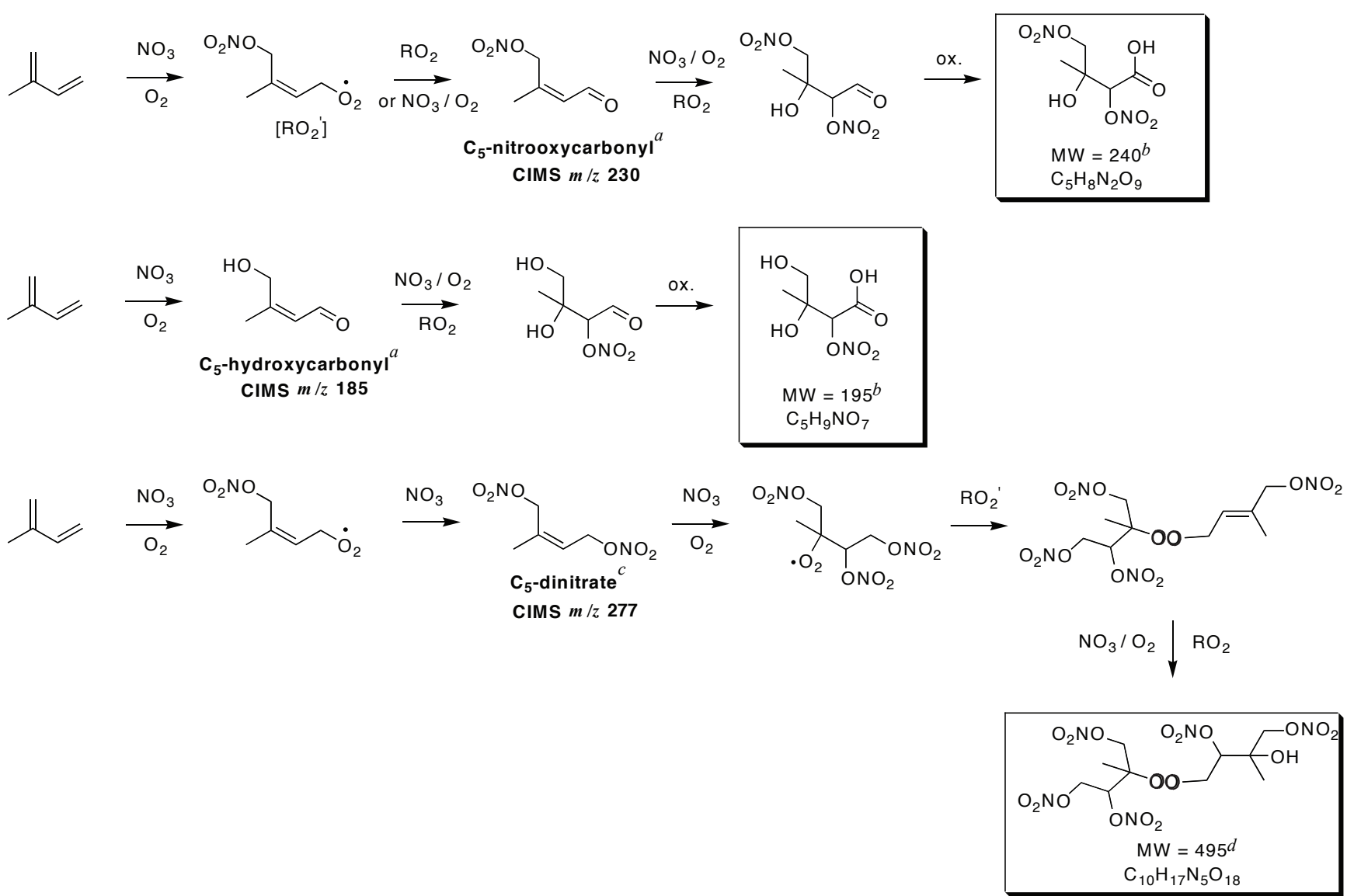

Fig. 17. Proposed mechanism for SOA formation from the formation and decay of the $\mathrm{C}_{5}$-nitrooxycarbonyl, $\mathrm{C}_{5}$-hydroxycarbonyl, and $\mathrm{C}_{5}$ dinitrate first-generation products formed from the isoprene $+\mathrm{NO}_{3}$ reaction. Boxes indicate UPLC/(-)ESI-TOFMS detected SOA products; molecular formulas were confirmed by the accurate mass data provided by the UPLC/(-)ESI-TOFMS. Multiple structural isomers are possible, consistent with the multiple chromatographic peaks observed in the extracted ion chromatograms; however, only one structural isomer is shown for simplicity. ${ }^{a}$ These first-generation gas-phase products were previously observed by Skov et al. (1994) and Kwok et al. (1996); these gas-phase products were detected as the $\left[\mathrm{M}+\mathrm{CF}_{3} \mathrm{O}\right]^{-}$ion by the CIMS instrument. ${ }^{\mathrm{b}}$ These are minor SOA products, confirming that the further oxidation of the $\mathrm{C}_{5}$-nitrooxycarbonyl and $\mathrm{C}_{5}$-hydroxycarbonyl first-generation products do not yield significant amounts of SOA. ${ }^{\mathrm{c}}$ This first-generation gas-phase product was previously observed by Werner et al. (1999); this gas-phase product was also detected as the $\left[\mathrm{M}+\mathrm{CF}_{3} \mathrm{O}^{-}\right]^{-}$ion by the CIMS instrument. ${ }^{\mathrm{d}}$ This particle-phase compound was detected as both its $[\mathrm{M}-\mathrm{H}]^{-}$and $\left[\mathrm{M}-\mathrm{H}+\mathrm{C}_{2} \mathrm{H}_{4} \mathrm{O}_{2}\right]^{-}$ions; the acetic acid adduct $\left(\left[\mathrm{M}-\mathrm{H}+\mathrm{C}_{2} \mathrm{H}_{4} \mathrm{O}_{2}\right]^{-}\right)$ion was the molecular ion (i.e. dominant ion).

such as $m / z 333$ (associated with MW 271 compound), 449 (MW 450 compound) and 554 (MW 495 compound) are not as strong in the excess isoprene experiment owing to the fact there is not enough $\mathrm{NO}_{3}$ in the system to allow for the formation of these highly oxidized compounds.

From the UPLC/(-)ESI-TOFMS (Table 2) and PILS/IC measurements, it appears that organic acids are not a major contributor to SOA formation from the oxidation of isoprene by $\mathrm{NO}_{3}$ radicals. The UPLC/(-)ESI-TOFMS technique detects only two minor organic acids at MW 195 and 240. Additionally, the PILS/IC technique does not detect large quantities of any small organic acids. The sum of formate, acetate, glycolate, lactate, oxalate, and pyruvate are usually be- tween $0.01-0.50 \mu \mathrm{g} \mathrm{m}^{-3}$. These observations are different from the SOA produced in the photooxidation of isoprene (under high- and low- $\mathrm{NO}_{\mathrm{x}}$ conditions), in which a large number of organic acids, such as 2-methylglyceric, formic, and acetic acid, are observed (Surratt et al., 2006; Szmigielski et al., 2007). In the photooxidation experiments, the level of organic acids detected under low- $\mathrm{NO}_{\mathrm{x}}$ conditions is lower than under high- $\mathrm{NO}_{\mathrm{x}}$ conditions. The low- $\mathrm{NO}_{\mathrm{x}}$ isoprene $\mathrm{SOA}$ was previously found to also have a significant amount of organic peroxides, as detected in the current study (Table 3); however, organic peroxides detected previously in low- $\mathrm{NO}_{\mathrm{x}}$ isoprene SOA were not structurally elucidated through MS techniques performed in the present study (Table 2, Figs. 14- 
17), possibly owing to the lack of nitrooxy groups which seem to induce acidity and/or increase the adductive abilities of organic peroxides with acetic acid during the ESI-MS analysis. Overall, it appears that the isoprene- $\mathrm{NO}_{3} \mathrm{SOA}$ is much more similar to the previously studied low- $\mathrm{NO}_{\mathrm{x}}$ isoprene SOA. More specifically, it appears that both contain a large amount of organic peroxides, organosulfates (if conducted in the presence of sulfate seed aerosol), and neutral hydroxylated compounds, such as the hydroxynitrates observed in Fig. 14 (e.g. MW 226 and 271 products).

As discussed earlier, the formation yields of ROOR from the reaction of two peroxy radicals is very low for small peroxy radicals (Kan et al., 1980; Niki et al., 1981, 1982; Wallington et al., 1989; Tyndall et al., 1998, 2001). However, according to both gas- phase and aerosol-phase data in this study, it appears that the $\mathrm{RO}_{2}+\mathrm{RO}_{2}$ reaction (self reaction or cross-reaction) in the gas phase yielding ROOR products is an important SOA formation pathway. Such reaction has been proposed to form low-volatility diacyl peroxides in the SOA formed from cyclohexene ozonolysis (Ziemann, 2002). In the case of self-reaction of peroxy radicals, the molecular weight of the product is essentially doubled, providing an efficient way to form products of low volatility. Based on the iodiometric spectroscopic method the contributions of peroxides (ROOH+ROOR) to the total SOA formed is $17-32 \%$ (Table 3 ). We can estimate the mass yield of peroxides based on their percentage contribution to total SOA and the SOA yield for each of the experiments in Table 3. It is found that the mass yield of peroxides range from $\sim 6-10 \%$. For the two experiments (i.e., 8/22/07 and 10/24/07) that are carried out under similar conditions as those in the yield experiments, the mass yield of peroxide is $8 \%$.

Based on the shape of the Odum yield curve (Fig. 3), it is expected that the products are semivolatile. Hence, the relatively large contribution of nonvolatile peroxides in the aerosol phase appears to be inconsistent with the observed yield curve behavior. It is evident from the UPLC/(-)ESITOFMS data that there exists a wide array of peroxides in the aerosol composition, however, we need to caution that there are large uncertainties associated with the quantification of peroxides owing to the lack of authentic standards. Based on the standard deviations of the measurements, the uncertainty is at least $10 \%$, yet if we take into account the following factors it is expected that the true uncertainty would be larger. In estimating the percentage contribution of peroxides, an average molecular weight of 433 for peroxides is used. The peroxides formed would largely depend on the branching ratio of various reactions and this number may not reflect the molecular weights of the wide array of peroxides formed. Also, the iodiometric spectroscopic method does not allow the distinction between $\mathrm{ROOH}$ and ROOR products. Hence, the contribution of the low volatility ROOR products may not be as high as estimated. $\mathrm{ROOH}$ standards were run in the ESI-TOFMS to examine the possibility of ROOH further reacting in the mass spectrometer to form ROOR and no ROOR products were detected. As mentioned before, it appears that the presence of nitrooxy groups in ROOR products aids their detection in the MS. Since the ROOH standards used do not have a nitrooxy group, unfortunately we cannot rule out the possibility that ROOR products are formed but just not being detected. Finally, it is worth noting that the initial isoprene concentrations in the yield experiments are much lower than those experiments in which SOA composition is measured. In performing the yield experiments, the initial isoprene concentrations are kept relatively low so as to be closer to atmospheric levels. Because of the lower initial isoprene concentration (hence lower aerosol loading), the partitioning of various products would be different and it is likely that level of peroxides would be lower in the yield experiments. Nevertheless, the higher concentration experiments are necessary to produce enough aerosols for filter analysis and to map out the complete spectrum of oxidation products.

To fully elucidate the relationship between the actual products identified and those inferred from fitting the yield data would require a modeling study that is beyond the scope of this work. However, we emphasize that there are large uncertainties associated with the quantification of peroxides and it is likely that their contributions to total SOA can be overestimated. Indeed, if the mass yield for these nonvolatile peroxides were lower (for instance, $\sim 2 \%$ ), this would agree well with the observed yield curve behavior. The measurement of peroxides certainly warrants further study. This work serves as a good example in showing that caution must be taken when interpreting experiments with low aerosol yields, especially when a relatively minor pathway may be responsible for forming the aerosols.

\section{Approximate estimate of global production of SOA from isoprene $+\mathrm{NO}_{3}$}

The global chemical transport model GEOS-Chem (v. 704-11) (http://www-as.harvard.edu/chemistry/trop/geos/) is used to estimate, roughly, global SOA formation from the isoprene $+\mathrm{NO}_{3}$ reaction. The current version of GEOS-Chem treats mechanistically SOA formation from isoprene+OH, monoterpenes and sesquiterpenes, and aromatics; here we will estimate $\mathrm{SOA}$ formation from isoprene $+\mathrm{NO}_{3}$ by using an approximate, uniform SOA yield of $10 \%$ (corresponding to $\mathrm{M}_{o} \cong 10 \mu \mathrm{g} \mathrm{m}^{-3}$ in Fig. 3 ). It is noted that this yield is quite uncertain and the importance of peroxy radical self reactions in this study suggest that the SOA yield in the atmosphere will be highly sensitive to the nature of the nighttime peroxy radical chemistry. Here, we seek to obtain only a "back-ofthe-envelope" estimate.

Two global isoprene emissions are available in GEOSChem: GEIA (Global Emission Inventory Activity) (Guenther et al., 1995) and MEGAN (Model of Emissions and Gases from Nature) (Guenther et al., 2006). Both models require, as input, meteorological data such as temperature 
to calculate the amount isoprene emitted. For the present estimate, the meteorological fields employed by $\mathrm{Wu}$ et al. (2007), generated by the Goddard Institute for Space Studies (GISS) General Circulation Model III, are used. Meteorological conditions correspond approximately to those of year 2000.

Table 4 presents the annual emissions of isoprene as predicted by each of the emission models, together with the amount of isoprene predicted to react via $\mathrm{OH}, \mathrm{O}_{3}$, and $\mathrm{NO}_{3}$, the global burden, and lifetime. We note that there is a significant difference between the annual isoprene emissions predicted by the earlier and newer emission models. Isoprene+OH accounts for 300 to $400 \mathrm{Tg} \mathrm{yr}^{-1}$ of isoprene consumption. Henze et al. (2007) predict that annual SOA production from isoprene $+\mathrm{OH}$ is about $13 \mathrm{Tg} \mathrm{yr}^{-1}$ (based on the MEGAN inventory and GEOS-4 meteorological fields, which are assimilated fields from actual year 2004). Note that $\mathrm{SOA}$ production from isoprene+OH, or any other pathway for that matter, is sensitive to the production of SOA from other hydrocarbon precursors since gas-aerosol partitioning depends on the total organic aerosol mass.

If we take as a rough estimate a 10\% SOA yield from the isoprene+ $+\mathrm{NO}_{3}$ pathway from the results in Table 4, 2 to $3 \mathrm{Tg} \mathrm{yr}^{-1}$ of SOA results from isoprene $+\mathrm{NO}_{3}$. This rate of production would make $\mathrm{SOA}$ from isoprene $+\mathrm{NO}_{3}$ as significant as that from sesquiterpenes, biogenic alcohols, and aromatics, each of which is estimated to produce about 2 to $4 \mathrm{Tg} \mathrm{yr}^{-1}$ of SOA based on yields measured in chamber studies (Henze et al., 2007). As a reference, the global SOA production is estimated to be $10-70 \mathrm{Tg} \mathrm{yr}^{-1}$ (Kanakidou et al., 2005). Recently, Goldstein et al. (2007) provided several alternative approaches to estimate global SOA production: 510-910 $\mathrm{Tg} \mathrm{C} \mathrm{yr}^{-1}$ based on the global mass balance of VOC

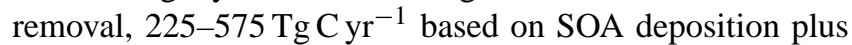
oxidation, $140-540{\mathrm{Tg} \mathrm{C} \mathrm{yr}^{-1}}^{-1}$ based on comparison with the sulfate budget, and $223-615 \mathrm{Tg} \mathrm{C} \mathrm{yr}^{-1}$ required to maintain the assumed global mean vertical SOA distribution. If we assume mass carbon/mass organics $=0.5$, the lower limit for SOA production from these estimates would be $280 \mathrm{Tg} \mathrm{yr}^{-1}$, which is much larger than that estimated from chamber SOA yields. Still, the $3 \mathrm{Tg} \mathrm{yr}^{-1}$ of SOA estimated for the isoprene $+\mathrm{NO}_{3}$ system is worth noticing. Owing to efficient photodissociation, $\mathrm{NO}_{3}$ achieves its highest concentrations at night. By contrast, isoprene emissions are assumed to be zero at night in both emission models. Consequently, the isoprene $+\mathrm{NO}_{3}$ reaction occurs only at night, involving isoprene that remains unreacted after each daytime period.

We caution that the estimates above are obtained at the crudest level of approximation, in which a globally uniform SOA yield of $10 \%$ from isoprene $+\mathrm{NO}_{3}$ is applied. As we note from Table 4, there is also as substantial difference between predictions of the two available isoprene emission models; the more recent MEGAN model represents an improved level of understanding over the earlier GEIA model. Predictions of SOA formation from the isoprene $+\mathrm{NO}_{3}$ path-
Table 4. Global estimation of isoprene using GEOS-Chem.

\begin{tabular}{lll}
\hline \multicolumn{3}{c}{ Emission Model } \\
\hline & GEIA $^{\mathrm{a}}$ & MEGAN $^{\mathrm{b}}$ \\
\hline Isoprene emission (Tg/y) & 507 & 389 \\
Global isoprene burden (Tg) & 1.7 & 1.7 \\
Isoprene lifetime (days) & 1.2 & 1.6 \\
Isoprene reacted (Tg/y) by & & \\
Isoprene+OH & 407 & 304 \\
Isoprene+O & 69 & 62 \\
Isoprene $+\mathrm{NO}_{3}$ & 29 & 21 \\
\hline
\end{tabular}

a Modification of GEIA for GEOS-Chem are described at Bey et al. (2001c). Original GEIA reference is Guenther et al. (1995).

b Guenther et al. (2006).

way are, of course, highly dependent on ambient $\mathrm{NO}_{3}$ radical concentrations. Nitrate radical concentrations predicted in the current simulations vary from about $0.1 \mathrm{ppt}$ in remote regions of South America to $20 \mathrm{ppt}$ or more in the southeastern USA (in August). Future work will address the simulation of SOA formation from isoprene $+\mathrm{NO}_{3}$ following the microphysical treatment in GEOS-Chem.

\section{Implications}

We report a series of chamber experiments investigating the formation of secondary organic aerosols from the reaction of isoprene with nitrate radicals. For an initial isoprene concentration of 18.4 to $101.6 \mathrm{ppb}$, the SOA yield ranges from $4.3 \%$ to $23.8 \%$ (typical yield experiments). The SOA yield from the slow $\mathrm{N}_{2} \mathrm{O}_{5}$ injection experiment $\left(\mathrm{RO}_{2}+\mathrm{RO}_{2}\right.$ reaction dominates) is much higher than that from the slow isoprene injection experiment $\left(\mathrm{RO}_{2}+\mathrm{NO}_{3}\right.$ dominates), implying that $\mathrm{RO}_{2}+\mathrm{RO}_{2}$ is a more effective channel of forming SOA. The SOA yield from the slow $\mathrm{N}_{2} \mathrm{O}_{5}$ experiment is roughly the same as that in the typical yield experiments, suggesting that SOA yields obtained in this study likely represent conditions in which peroxy-peroxy radical reactions are favored. Using a uniform SOA yield of $10 \%$ (corresponding to $\mathrm{M}_{o} \cong 10 \mu \mathrm{g} \mathrm{m}^{-3}$ ), $\sim 2$ to $3 \mathrm{Tg} \mathrm{yr}^{-1}$ of SOA results from isoprene $+\mathrm{NO}_{3}$, which is about $1 / 4$ of the amount of SOA estimated to be formed from isoprene+OH $\left(\sim 13 \mathrm{Tg} \mathrm{yr}^{-1}\right)$ (Henze et al., 2007).

The extent to which the results from this study can be applied to conditions in the atmosphere depends on the relative importance of the various reaction pathways of peroxy radicals in the nighttime atmosphere: $\mathrm{RO}_{2}+\mathrm{RO}_{2}, \mathrm{RO}_{2}+\mathrm{NO}_{3}$, $\mathrm{RO}_{2}+\mathrm{NO}$, and $\mathrm{RO}_{2}+\mathrm{HO}_{2}$. However, the fate of peroxy radicals in the atmosphere is uncertain owing to the large uncertainties in the reaction rate constants and ambient concentrations of the radicals (Skov et al., 1992; Kirchner and Stockwell, 1996; Bey et al., 2001a, b; Vaughan et al., 2006). For 
instance, a modeling study by Kirchner and Stockwell (1996) suggests that the $\mathrm{RO}_{2}+\mathrm{NO}_{3}$ reaction is the dominant pathway at night; $77 \%$ and $90 \%$ of the total $\mathrm{RO}_{2}$ at night is predicted to react with $\mathrm{NO}_{3}$ in polluted atmosphere and rural air (mixed with aged air), respectively. The other pathways are not as important; while $\mathrm{RO}_{2}+\mathrm{RO}_{2}$ can account for about $8-23 \%$ of the total $\mathrm{RO}_{2}$ reaction, $\mathrm{RO}_{2}+\mathrm{HO}_{2}$ only accounts for $6-10 \%$, and $\mathrm{RO}_{2}+\mathrm{NO}$ is minimal $(0-1 \%)$ (Kirchner and Stockwell, 1996). These results are at odds with the study by Bey et al. (2001a,b), which suggests that $\mathrm{NO}_{3}$ radicals are not involved significantly in the propagation of $\mathrm{RO}_{2}$ radicals $(<5 \%)$. Instead, $\mathrm{RO}_{2}+\mathrm{NO}(77 \%)$ and $\mathrm{RO}_{2}+\mathrm{RO}_{2}(40 \%)$ are dominant in the mixed layer in the urban and rural areas, respectively. Although there is no definite conclusion as which reaction pathway dominates in the nighttime atmosphere, both studies seem to suggest that $\mathrm{RO}_{2}+\mathrm{HO}_{2}$ is relatively not as important. In this work, we investigated situations in which either $\mathrm{RO}_{2}+\mathrm{RO}_{2}$ or $\mathrm{RO}_{2}+\mathrm{NO}_{3}$ dominates. In both cases the $\mathrm{RO}_{2}+\mathrm{HO}_{2}$ reaction is expected to be a minor channel and thus this is in line with the modeling studies. Although $\mathrm{RO}_{2}+\mathrm{NO}$ is not considered in this study, this reaction produces the same alkoxy radical as in the $\mathrm{RO}_{2}+\mathrm{NO}_{3}$ reaction. It is likely that it would result in similar products as those in the case where the $\mathrm{RO}_{2}+\mathrm{NO}_{3}$ reaction dominates. Currently, only the reaction rate constants for small, relatively simple $\mathrm{RO}_{2}$ radicals with $\mathrm{NO}_{3}$ radicals have been reported (e.g. Biggs et al., 1994; Daele et al., 1995; CanosaMas et al., 1996; Vaughan et al., 2006) and they are roughly in the range of $(1-3) \times 10^{-12} \mathrm{~cm}^{3}$ molecule $\mathrm{e}^{-1} \mathrm{~s}^{-1}$. With the oxidation of various volatile organic compounds by $\mathrm{O}_{3}$ and $\mathrm{NO}_{3}$ under nighttime conditions, it is expected that multifunctional peroxy radicals would be prevalent; the reaction rates of these complex peroxy radicals warrant future study. Furthermore, more field measurements on the concentrations of various radicals would also help to constrain the relative importance of the different reaction pathways.

In this study, we have shown that the formation of ROOR from the reaction of two peroxy radicals is an effective SOAforming channel based on gas-phase data and elemental SOA composition data. If the results from this study can be applied to other systems (i.e., the reaction of $\mathrm{NO}_{3}$ radicals with other volatile organic compounds), the organic peroxides could possibly be formed in all systems; they may not have been identified previously owing to the lack of suitable analytical techniques such as accurate mass measurements from high resolution MS. Since the formation of ROOR from two peroxy radicals has always been considered as a minor channel, the reaction has not been widely studied. Ghigo et al. (2003) ruled out the direct formation of products (RO, $\mathrm{ROH}, \mathrm{RCHO}$ ) from the tetroxide intermediate ROOOOR. Instead, they proposed that the tetroxide breaks up into a weakly bound complex of two $\mathrm{RO}$ radicals and $\mathrm{O}_{2}$, which then fall apart or undergoes intersystem crossing to form the corresponding alcohol and carbonyl products. The formation of ROOR was not discussed in Ghigo et al. (2003) owing to little experimental evidence for the production of ROOR. However, the observation of ROOR formation in this study suggests that this reaction does occur and is potentially important for aerosol formation. As pointed out by Dibble (2008), the mechanism proposed by Ghigo (2003) would seem to allow for easy production of ROOR from the RO-RO-O ${ }_{2}$ complex. Therefore, it appears that there are at least two possible pathways for ROOR formation: it can either be formed through the RO-RO-O ${ }_{2}$ complex as suggested by Dibble (2008), or there may exist a direct pathway for ROOR formation from ROO+ROO. Certainly more work is needed regarding the formation, detection, and quantification of ROOR products.

It is also worth noting that while most $\mathrm{NO}_{3}$ chemistry occurs at night, it can also be important during the day at specific locations. Recently, a study by Fuentes et al. (2007) suggested substantial formation of $\mathrm{NO}_{3}$ radicals can take place in forested environments with moderate to high levels of BVOC production, resulting in a significant oxidation of isoprene and terpenes by $\mathrm{NO}_{3}$ radicals. For instance, approximately $60 \%$ of the terpenes react with $\mathrm{NO}_{3}$ radicals within the canopy. Clearly, more study is needed to evaluate the importance of $\mathrm{NO}_{3}$ chemistry of biogenic hydrocarbons under different environments and time of the day.

Acknowledgements. This research was funded by US Department of Energy Biological and Environmental Research Program DE-FG02-05ER63983. This material is based in part on work supported by the National Science Foundation (NSF) under grant ATM-0432377. The Waters LCT Premier XT time-of-flight mass spectrometer interfaced to a Waters UPLC system was purchased in 2006 with a grant from the National Science Foundation, Chemistry Research Instrumentation and Facilities Program (CHE-0541745). The LCQ Ion Trap mass spectrometer was purchased in 1997 with funds from the National Science Foundation through the CRIF program (CHE-9709233). J. D. Surratt is supported in part by the US EPA under the STAR Graduate Fellowship Program. A. J. Kwan and H. O. T. Pye acknowledge the support of NSF graduate research fellowships. The authors would like to thank C. D. Vecitis, J. Cheng, and M. R. Hoffmann for use of and aid with their ozonizer and UV-VIS spectrometer; to K. Takematsu and $\mathrm{M}$. Okumura for helpful advice on preparing $\mathrm{N}_{2} \mathrm{O}_{5}$; to J. H. Kroll and M. Claeys for helpful discussions and suggestions; to M. N. Chan for assistance with filter sample collection; to H. G. Kjaergaard and F. Paulot for performing the quantum calculations and estimating the sensitivities of CIMS to various gas-phase products; and to $\mathrm{Y}$. Yu and the reviewers for helpful comments on the manuscript.

Edited by: S. Martin 


\section{References}

Alfarra, M. R., Paulsen, D., Gysel, M., Garforth, A. A., Dommen, J., Prevot, A. S. H., Worsnop, D. R., Baltensperger, U., and Coe, H.: A mass spectrometric study of secondary organic aerosols formed from the photooxidation of anthropogenic and biogenic precursors in a reaction chamber, Atmos. Chem. Phys., 6, 52795293, 2006, http://www.atmos-chem-phys.net/6/5279/2006/.

Bahreini, R., Keywood, M. D., Ng, N. L., Varutbangkul, V., Gao, S., Flagan, R. C., and Seinfeld, J. H. Measurements of secondary organic aerosol (SOA) from oxidation of cycloalkenes, terpenes, and $\mathrm{m}$-xylene using an Aerodyne aerosol mass spectrometer. Environ. Sci. Technol., 39, 5674-5688, 2005.

Barnes, I., Bastian, V., Becker, K. H., and Tong, Z.: Kinetics and products of the reactions of $\mathrm{NO}_{3}$ with monoalkenes, dialkenes, and monoterpenes, J. Phys. Chem., 94, 2413-2419, 1990.

Berndt, T. and Böge, O.: Gas-Phase reaction of $\mathrm{NO}_{3}$ radicals with isoprene: A kinetic and mechanistic study, Inter. J. Chem. Kinet., 29, 755-765, 1997.

Bey, I., Aumont, B., and Toupance, G.: A modeling study of the nighttime radical chemistry in the lower continental troposphere. 1. Development of a detailed chemical mechanism including nighttime chemistry, J. Geophys. Res., 106(D9), 99599990, 2001a.

Bey, I., Aumont, B., and Toupance, G.: A modeling study of the nighttime radical chemistry in the lower continental troposphere. 2. Origin and evolution of $\mathrm{HO}_{x}$, J. Geophys. Res., 106(D9), 9991-10001, 2001b.

Bey, I., Jacob, D. J., Yantosca, R. M., Logan, J. A., Field, B. D., Fiore, A. M., Li, Q. B., Liu, H. G. Y., Mickley, L. J., and Schultz, M. G.: Global modeling of tropospheric chemistry with assimilated meteorology: Model description and evaluation, J. Geophys. Res., 106(D19), 23 073-23 095, 2001c.

Biggs, P., Canosa-Mas, C. E., Fracheboud, J. M., Shallcross, D. E., and Wayne, R. P.: Investigation into the kinetics and mechanisms of the reaction of $\mathrm{NO}_{3}$ with $\mathrm{CH}_{3}$ and $\mathrm{CH}_{3} \mathrm{O}$ at $298 \mathrm{~K}$ between 0.6 Torr and 8.5 Torr - is there a chain decomposition mechanism in operation, J. Chem. Soc., Faraday Trans., 90, 1197-1204, 1994.

Brown, S. S., Ryerson, T. B., Wollny, A. G., Brock, C. A., Peltier, R., Sullivan, A. P., Weber, R. J., Dube, W. P., Trainer, M., Meagher, J. F., Fehsenfeld, F. C., and Ravishankara, A. R.: Variability in nocturnal nitrogen oxide processing and its role in regional air quality, Science, 311, 5757, 67-70, 2006.

Canosa-Mas, C. E., Flugge, M. L., King, M. D., and Wayne, R. P.: An experimental study of the gas-phase reaction of the $\mathrm{NO}_{3}$ radical with $\alpha$ s $\beta$ tunsaturated carbonyl compounds, Phys. Chem. Chem. Phys., 7. 643-650, 2005.

Canosa-Mas, C. E., King, M. D., Lopez, R., Percival, C. J., Wayne, R. P., Shallcross, D. E., Pyle, J. A., and Daele, V.: Is the reaction $\mathrm{CH}_{3} \mathrm{C}(\mathrm{O}) \mathrm{O}_{2}$ and $\mathrm{NO}_{3}$ important in the night-time troposphere? J. Chem. Soc., Faraday Trans., 92, 2211-2222, 1996.

Carslaw, N., Carpenter, L. J., Plane, J. M. C., Allan, B. J., Burgess, R. A., Clemitshaw, K. C., Coe, H., and Penkett, S. A.: Simultaneous measurements of nitrate and peroxy radicals in the marine boundary layer, J. Geophys. Res., 102, 18 917-18 933. 1997.

Carter, W. P. L. and Atkinson, R.: Development and evaluation of a detailed mechanism for the atmospheric reactions of isoprene and $\mathrm{NO}_{\mathrm{x}}$, Int. J. Chem. Kinet., 28, 497-530, 1996.

Claeys, M., Graham, B., Vas, G., Wang, W., Vermeylen, R., Pashyn- ska, V., Cafmeyer, J., Guyon, P., Andreae, M. O., Artaxo, P., and Maenhaut, W.: Formation of secondary organic aerosols through photooxidation of isoprene, Science, 303, 1173-1176, 2004.

Cocker III, D. R., Flagan, R. C., and Seinfeld, J. H.: State-of-theart chamber facility for studying atmospheric aerosol chemistry, Environ. Sci. Technol., 35, 2594-2601. 2001.

Crounse, J. D., McKinney, K. A., Kwan, A. J., and Wennberg, P. O.: Measurements of gas-phase hydroperoxides by chemical ionization mass spectrometry, Anal. Chem., 78, 6726-6732, 2006.

Curren, K., Gillespie, T., Steyn, D., Dann, T., and Wang, D.: Biogenic isoprene in the Lower Fraser Valley, British Columbia, J. Geophys. Res., 103, D19, 25467-25477, 1998.

Daele, V., Laverdet, G., Lebras, G., and Poulet, G.: Kinetics of the reactions of $\mathrm{CH}_{3} \mathrm{O}+\mathrm{NO}, \mathrm{CH}_{3} \mathrm{O}+\mathrm{NO}_{3}$, and $\mathrm{CH}_{3} \mathrm{O}_{2}+\mathrm{NO}_{3}$, J. Phys. Chem., 99, 1470-1477, 1995.

Davidson, J. A., Viggiano, A. A., Howard, C. J., Fehsenfeld, F. C., Albritton, D. L., and Ferguson, E. E.: Rate constants for the reaction of $\mathrm{O}_{2}^{+}, \mathrm{NO}_{2}^{+}, \mathrm{NO}^{+}, \mathrm{H}_{3} \mathrm{O}^{+}, \mathrm{CO}_{3}^{-}, \mathrm{NO}_{2}^{-}$, and halide ions with $\mathrm{N}_{2} \mathrm{O}_{5}$ at $300 \mathrm{~K}$, J. Chem. Phys., 68, 2085-2087, 1978.

Dibble, T. S.: Isomerization of $\mathrm{OH}$-isoprene adducts and hydroxyalkoxy isoprene radicals, J. Phys. Chem., 106(28), 6643-6650, 2002.

Dibbe T. S.: Failures and limitations of quantum chemistry for two key problems in the atmospheric chemistry of peroxy radicals, Atmos. Environ., in press, 2008.

Docherty, K., Wu, W., Lim, Y., and Ziemann, P.: Contributions of Organic Peroxides to Secondary Aerosol Formed from Reactions of Monoterpenes with $\mathrm{O}_{3}$, Environ. Sci. Technol., 39, 4049-4059, 2005.

Dommen, J., Metzger, A., Duplissy, J., Kalberer, M., Alfarra, M. R., Gascho, A., Weingartner, E., Prevot, A. S. H., Verheggen, B., and Baltensperger, U.: Laboratory observation of oligomers in the aerosol from isoprene/ $\mathrm{NO}_{x}$ photooxidation, Geophys. Res. Lett., 33, L13805, doi:10.1029/2006GL026523, 2006.

Edney, E. O., Kleindienst, T. E., Jaoui, M., Lewandowski, M., Offenberg, J. H., Wang, W., and Claeys, M.: Formation of 2-methyl tetrols and 2-methylglyceric acid in secondary organic aerosol from laboratory irradiated isoprene/ $\mathrm{NO}_{\mathrm{x}} / \mathrm{SO}_{2} /$ air mixtures and their detection in ambient $\mathrm{PM}_{2.5}$ samples collected in the eastern United States, Atmos. Environ., 39, 5281-5289, 2005.

Fan, J. and Zhang, R.: Atmospheric oxidation mechanism of isoprene, Environ. Chem., 1, 140-149, doi:10.1071/EN04045, 2004.

Fuentes, J. D., Wang, D., Rowling, D. R., Potosnak, M., Monson, R. K., Goliff, W. S., and Stockwell, W. R.: Biogenic hydrocarbon chemistry within and above a mixed deciduous forest, J. Atmos. Chem., 56, 165-185. 2007.

Gao, S., Keywood, M. D., Ng, N. L., Surratt, J. D., Varutbangkul, V., Bahreini, R., Flagan, R. C., and Seinfeld, J. H.: Low molecular weight and oligomeric components in secondary organic aerosol from the ozonolysis of cycloalkenes and $\alpha$-pinene, J. Phys. Chem. A, 108, 10 147-10 164, 2004a.

Gao, S., Ng, N. L., Keywood, M. D., Varutbangkul, V., Bahreini, R., Nenes, A., He, J., Yoo, K. Y., Beauchamp, J. L., Hodyss, R. P., Flagan, R. C., and Seinfeld, J. H.: Particle phase acidity and oligomer formation in secondary organic aerosol, Environ. Sci. Technol., 38, 6582-6589, 2004b.

Gao, S., Surratt, J. D., Knipping, E. M., Edgerton, E. S., Shahgholi, M., and Seinfeld, J. H.: Characterization of polar organic com- 
ponents in fine aerosols in the southeastern United States: Identity, origin, and evolution, J. Geophys. Res., 111, D14314, doi:10.1029/2005JD006601, 2006.

Ghigo, G., Maranzana, A., and Tonachini, G.: Combustion and atmospheric oxidation o hydrocarbons: Theoretical study of the methyl peroxyl self-reaction, J. Chem. Phys., 118, 23, 2003.

Goldstein, A. H. and Galbally, I. E.: Known and unexplored organic constituents in the earth's atmosphere, Environ. Sci. Technol., 41, 1514-1521, 2007.

Gong, H., Matsunaga, A., and Ziemann, P.: Products and mechanism of secondary organic aerosol formation from reactions of linear alkenes with $\mathrm{NO}_{3}$ radicals, J. Phys. Chem., 109, 43124324, 2005.

Gómez-González, Y., Surratt, J. D., Cuyckens, F., Szmigielski, R., Vermeylen, R., Jaoui, M., Lewandowski, M., Offenberg, J. H., Kleindienst, T. E., Edney, E. O., Blockhuys, F., Van Alsenoy, C., Maenhaut, W. and Claeys, M.: Characterization of organosulfates from the photooxidation of isoprene and unsaturated fatty acids in ambient aerosol using liquid chromatography/(-) electrospray ionization mass spectrometry, J. Mass Spectrom., 43(3), 371-382, doi:10.1002/jms.1329, 2007.

Guenther, A., Hewitt, C. N., Erickson, D., Fall, R., Geron, C., Graedel, T., Harley, P., Klinger, L., Lerdau, M., Mckay, W. A., Pierce, T., Scholes, B., Steinbrecher, R., Tallamraju, R., Taylor, J., and Zimmerman, P.: A global-model of natural volatile organic compound emissions, J. Geophys. Res., 100(D5), 88738892, 1995.

Guenther, A., Karl, T., Harley, P., Wiedinmyer, C., Palmer, P. I., and Geron, C.: Estimates of global terrestrial isoprene emissions using MEGAN (Model of Emissions of Gases and Aerosols from Nature), Atmos. Chem. Phys., 6, 3181-3210, 2006, http://www.atmos-chem-phys.net/6/3181/2006/.

Heintz, F., Platt, U., Flentje, H., and Dubois, R.: Long-term observation of nitrate radicals at the tor station, Kap Arkona (Rugen), J. Geophys. Res., 101(D17), 22 891-22 910, 1996.

Henze, D. K., Seinfeld, J. H., Ng, N. L., Kroll, J. H., Fu, T.-M., Jacob, D. J., and Heald, C. L.: Global modeling of secondary organic aerosol formation from aromatic hydrocarbons: high- vs. low-yield pathways, Atmos. Chem. Phys., 8, 2405-2420, 2008, http://www.atmos-chem-phys.net/8/2405/2008/.

Horowitz, L. W., Fiore, A. M., Milly, G. P., Cohen, R. C., Perring, A., Wooldridge, P. J., Hess, P.G., Emmons, L. K., and Lamarque, J.: Observational constraints on the chemistry of isoprene nitrates over the eastern United States, J. Geophys. Res., 112, D12S08, doi:10.1029/2006JD007747, 2007.

Iinuma, Y., Müller, C., Berndt, T., Böge, O., Claeys, M., and Herrmann, H.: Evidence for the existence of organosulfates from $\beta$-pinene ozonolysis in ambient secondary organic aerosol, Environ. Sci. Technol., 41, 6678-6683, $2007 \mathrm{~b}$.

Iinuma, Y., Müller, C., Böge, O., Gnauk, T., and Herrmann, H.: The formation of organic sulfate esters in the limonene ozonolysis secondary organic aerosol (SOA) under acidic conditions, Atmos. Environ., 41, 5571-5583, 2007a.

Jay, K. and Stieglitz, L.: The gas phase addition of $\mathrm{NO}_{\mathrm{x}}$ to olefins, Chemosphere, 19, 1939-1950, 1989.

Jayne, J. T., Leard, D. C., Zhang, X., Davidovits, P., Smith, K. A., Kolb, C. E., and Worsnop, D. W.: Development of an Aerosol Mass Spectrometer for size and composition analysis of submicron particles, Aerosol Sci. Technol., 33, 49-70, 2000.
Kan, C. S., Calvert, J. G., and Shaw, J. H.: Reactive channels of the $\mathrm{CH}_{3} \mathrm{O}_{2}-\mathrm{CH}_{3} \mathrm{O}_{2}$ reaction, J. Phys. Chem., 84, 3411-3417, 1980.

Kanakidou, M., Seinfeld, J. H., Pandis, S. N., Barnes, I., Dentener, F. J., Facchini, M. C., Van Dingenen, R., Ervens, B., Nenes, A., Nielsen, C. J., Swietlicki, E., Putaud, J. P., Balkanski, Y., Fuzzi, S., Horth, J., Moortgat, G. K., Winterhalter, R., Myhre, C. E. L., Tsigaridis, K., Vignati, E., Stephanou, E. G., and Wilson, J.: Organic aerosol and global climate modelling: a review, Atmos. Chem. Phys., 5, 1053-1123, 2005,

http://www.atmos-chem-phys.net/5/1053/2005/.

Keywood, M. D., Varutbangkul, V., Bahreini, R., Flagan, R. C., and Seinfeld, J. H.: Secondary organic aerosol formation from the ozonolysis of cycloalkenes and related compounds, Environ. Sci. Technol., 38, 4157-4164, 2004.

Kirchner, F. and Stockwell, W. R.: Effect of peroxy radical reactions on the predicted concentrations of ozone, nitrogenous compounds, and radicals, J. Geophys. Res., 101(D15), 21007 $21022,1996$.

Knopf, D. A., Mak, J., Gross, S., and Bertram, A. K.: Does atmospheric processing of saturated hydrocarbon surfaces by $\mathrm{NO}_{3}$ lead to volatilization?, Geophys. Res. Lett., 33, L17816, doi:10.1029/2006GL026884, 2006.

Kroll, J. H., Ng, N. L., Murphy, S. M., Flagan, R. C., and Seinfeld, J. H.: Secondary organic aerosol formation from isoprene photooxidation under high- $\mathrm{NO}_{\mathrm{x}}$ conditions, J. Geophys. Res., 32, L18808, doi:10.1029/2005GL023637, 2005.

Kroll, J. H., Ng, N. L., Murphy, S. M., Flagan, R. C., and Seinfeld. J. H.: Secondary organic aerosol formation from isoprene photooxidation, Environ. Sci. Technol., 40. 1869-1877, 2006.

Kwok, E. S. C., Aschmann, S. M., Arey, J., and Atkinson, R.: Product formation from the reaction of the $\mathrm{NO}_{3}$ radical with isoprene and rate constants for the reactions of methacrolein and methyl vinyl ketone with the $\mathrm{NO}_{3}$ radical, Inter. J. Chem. Kinet. 28, 925-934, 1996.

Liggio, J. and Li, S. M.: Organosulfate formation during the uptake of pinonaldehyde on acidic sulfate aerosols, Geophys. Res. Lett., 33, L13808, doi:10.1029/2006GL026079, 2006.

Liggio, J., Li, S. M., and McLaren, R.: Heterogeneous reactions of glyoxal on particulate matter: Identification of acetals and sulfate esters, Environ. Sci. Technol., 39, 1532-1541, 2005.

Lightfoot, P. D., Cox, R..A., Crowley, J. N., Destriau, M. Hayman, G. D., Jenkin, M. E., Moortgat G. K., and Zabel, F.: Organic peroxy radicals - kinetics, spectroscopy and tropospheric chemistry, Atmos. Environ., 26, 1805-1961, 1992.

Moise, T., Talukdar, R. K., Frost, G. J., Fox, R. W., and Rudich, Y.: Reactive uptake of $\mathrm{NO}_{3}$ by liquid and frozen organics, J. Geophys. Res., 107(D2), 4014, doi:10.1029/2001JD000334, 2002.

Ng, N. L., Chhabra, P. S., Chan, A. W. H., Surratt, J. D., Kroll, J. H., Kwan, A. J., McCabe, D. C., Wennberg, P. O., Sorooshian, A., Murphy, S. M., Dalleska, N. F., Flagan, R. C., and Seinfeld, J. H.: Effect of $\mathrm{NO}_{\mathrm{x}}$ level on secondary organic aerosol (SOA) formation from the photooxidation of terpenes, Atmos. Chem. Phys., 7, 5159-5174, 2007a,

http://www.atmos-chem-phys.net/7/5159/2007/.

Ng, N. L., Kroll, J. H., Chan, A. W. H., Chhabra, P. S., Flagan, R. C., and Seinfeld, J. H.: Secondary organic aerosol formation from $m$-xylene, toluene, and benzene, Atmos. Chem. Phys., 7, 3909-3922, 2007b,

http://www.atmos-chem-phys.net/7/3909/2007/. 
Ng, N. L., Kroll, J. H., Keywood, M. D., Bahreini, R., Varutbangkul, V., Flagan, R. C., Seinfeld, J. H., Lee, A., and Goldstein, A. H.: Contribution of first- versus second-generation products to secondary organic aerosols formed in the oxidation of biogenic hydrocarbons, Environ. Sci. Technol., 40, 2283-2297, 2006.

Niki, H, Maker, P. D., Savage, C. M., and Breitenbach L.P.: Fourier Transform Infrared studies of the self-reaction of $\mathrm{CH}_{3} \mathrm{O}_{2}$ radicals, J. Phys. Chem., 85, 877-881, 1981.

Niki, H, Maker, P. D., Savage, C. M., and Breitenbach L.P.: Fourier Transform Infrared studies of the self-reaction of $\mathrm{C}_{2} \mathrm{H}_{5} \mathrm{O}_{2}$ radicals, J. Phys. Chem., 86, 3825-3829, 1982.

Noda, J., Nyman, G., and Langer S.: Kinetics of the gas-phase reaction of some unsaturated alcohols with the nitrate radical, J. Phys. Chem., 106, 945-951, 2002.

Odum, J. R., Hoffmann, T., Bowman, F., Collins, D., R. C. Flagan, R. C., and Seinfeld, J. H.: Gas/particle partitioning and secondary organic aerosol yields, Environ. Sci. Technol., 30, 2580 2585, 1996.

Odum, J. R., Jungkamp, T. P. W., Griffin, R. J., Flagan, R. C., and Seinfeld, J. H.: The atmospheric aerosol-forming potential of whole gasoline vapor, Science, 276, 96-99, 1997a.

Odum, J. R., Jungkamp, T. P. W., Griffin, R. J., Forstner, H. J. L., Flagan, R. C., and Seinfeld, J. H.: Aromatics, reformulated gasoline and atmospheric organic aerosol formation, Environ. Sci. Technol., 31, 1890-1897, 1997b.

Paulot, F., Crounse, J. D., Kjaergaard, H. G., Kroll, J. H., Seinfeld, J. H., and Wennberg, P. O.: Isoprene photooxidation mechanism: resonance channels and implications for the production of nitrates and acids, accepted, Atmos. Chem. Phys. Discuss., 2008.

Paulson, S. E. and Seinfeld, J. H.: Development and evaluation of a photooxidation mechanism for isoprene, J. Geophys. Res., 97(D18), 20 703-20715, 1992.

Penkett, S. A., Burgess, R. A., Coe, H., Coll, I., Hov, Ø., Lindskog, A., Schmidbauer, N., Solberg, S., Roemer, M., Thijsse, T., Beck, J., and Reeves C. E.: Evidence for large average concentrations of the nitrate radical $\left(\mathrm{NO}_{3}\right)$ in Western Europe from the HANSA hydrocarbon database, Atmos. Environ., 41, 3465-3478, 2007.

Platt, U. and Janssen, C.: Observation and role of the free radicals $\mathrm{NO}_{3}, \mathrm{ClO}, \mathrm{BrO}$ and $\mathrm{IO}$ in the troposphere, Faraday Discuss., 100, 175-198, 1995.

Platt, U., Perner, D., Schroder, J., Kessler, C., and Toennissen, A.: The diurnal variation of $\mathrm{NO}_{3}$, J. Geophys. Res., 86, 11965 $11970,1981$.

Rudich, Y., Donahue, N. M., and Mentel, T. F.: Aging of organic aerosol: Bridging the gap between laboratory and field studies, Annu. Rev. Phys. Chem., 58, 321-352, 2007.

Sharkey, T. D., Singsaas, E. L., Vanderveer, P. J., and Geron, C.: Field measurements of isoprene emission from trees in response to temperature and light, Tree Physiol., 16, 649-654, 1996.

Skov, H., Benter, Th., Schindler, R. N., Hjorth, J., and Restelli, G.: Epoxide formation in the reactions of the nitrate radical with 2,3dimethyl-2-butene, cis- and trans-2-butene and isoprene, Atmos. Environ., 28, 1583-1592, 1994.

Skov, H., Hjorth, J., Lohse, C., Jensen, N. R. and Restelli, G.: Products and mechanisms of the reactions of the nitrate radical $\left(\mathrm{NO}_{3}\right)$ with isoprene, 1,3-butadiene and 2,3-dimethyl-1,3-butadiene in air, Atmos. Environ., 26A(15), 2771-2783, 1992.
Smith, N., Plane, J. M. C., Nien, C. F., and Solomon, P. A.: Nighttime radical chemistry in the San-Joaquin Valley, Atmos. Environ., 29, 2887-2897, 1995.

Sorooshian, A., Brechtel F. J., Ma, Y. L., Weber R. J., Corless, A., Flagan, R. C., and Seinfeld, J. H.: Modeling and characterization of a particle-into-liquid sampler (PILS), Aerosol Sci. Technol., 40, 396-409, 2006.

Starn, T. K., Shepson, P. B., Bertman, S. B., Riemer, D. D., Zika, R. G. and Olszyna, K.: Nighttime isoprene chemistry at an urbanimpacted forest site, J. Geophys. Res., 103(D17), 22 437-22 447, 1998.

Steinbacher, M., Dommen, J. Ordonez, C., Reimann, S., Gruebler, F. C., Staehelin, J., Andreani-Aksoyoglu, S., and Prevot, A. S. H.: Volatile organic compounds in the Po Bason. Part B: Biogenic VOCs, J. Atmos. Chem., 51, 293-315, 2005.

Stroud, C. A., Roberts, J. M., Williams E. J., Hereid, D., Angevine, W. M., Fehsenfeld, F. C., Wisthaler, A., Hansel, A., MartinezHarder, M., Harder, H., Brune, W. H., Hoenninger, G., Stutz, J., and White, A. B.: Nighttime isoprene trends at an urban forested site during the 1999 Southern Oxidant Study, J. Geophys. Res., 107(D16), 4291, doi:10.1029/2001JD000959, 2002.

Su, T. and Chesnavich, W. J.: Parametrization of the ion-polar molecule collision rate constant by trajectory calculations, The Journal of Chemical Physics, 76, 5183, 1982.

Suh, I., Lei, W., and Zhang, R.: Experimental and theoretical studies of isoprene reaction with $\mathrm{NO}_{3}$, J. Phys. Chem., 105, 64716478, 2001.

Surratt, J. D., Kroll, J. H., Kleindienst, T. E., Edney, E. O., Claeys, M., Sorooshian, A., Ng, N. L., Offenberg, J. H., Lewandowski, M., Jaoui, M., Flagan, R. C., and Seinfeld, J. H.: Evidence for organosulfates in secondary organic aerosol, Environ. Sci. Technol., 41, 517-527, 2007a.

Surratt, J. D., Lewandowski, M., Offenberg, J. H., Jaoui, M., Kleindienst, T. E., Edney, E. O., and Seinfeld, J. H.: Effect of acidity on secondary organic aerosol formation from isoprene, Environ. Sci. Technol., 41, 5363-5369, 2007 b.

Surratt, J. D., Murphy, S. M., Kroll, J. H., Ng, N. L., Hildebrandt, L., Sorooshian, A., Szmigielski, R., Vermeylen, R., Maenhaut, W., Claeys, M., Flagan, R. C., and Seinfeld, J. H.: Chemical composition of secondary organic aerosol formed from the photooxidation of isoprene, J. Phys. Chem. A, 110, 9665-9690, 2006.

Szmigielski, R., Surratt, J. D., Vermeylen, R., Szmigielska, K., Kroll, J. H., Ng, N. L., Murphy, S. M., Sorooshian, A., Seinfeld, J. H., and Claeys, M.: Characterization of 2-methylglyceric acid oligomers in secondary organic aerosol formed from the photooxidation of isoprene using trimethylsilylation and gas chromatography/ion trap mass spectrometry, J. Mass Spectrom., 42, 101-116, 2007.

Tyndall, G. S., Cox, R. A., Granier, C., Lesclaux, R., Moortgat, G. K., Pilling, M. J., Ravishankara, A. R., and Wallington, T. J.: Atmospheric chemistry of small peroxy radicals, J. Geophys. Res., 106(D11), 12 157-12 182, 2001.

Tyndall, G. S., Wallington, T. J., and Ball, J. C.: FTIR product study of the reactions of $\mathrm{CH}_{3} \mathrm{O}_{2}+\mathrm{CH}_{3} \mathrm{O}_{2}$ and $\mathrm{CH}_{3} \mathrm{O}_{2}+\mathrm{O}_{3}$, J. Phys. Chem., 102, 2547-2554, 1998.

Vaughan, S. Canosa-Mas, C. E., Pfrang, C., Shallcross, D. E., Watson, L., and Wayne, R. P.: Kinetic studies of reactions of the nitrate radical $\left(\mathrm{NO}_{3}\right)$ with peroxy radicals $\left(\mathrm{RO}_{2}\right)$ : an indirect 
source of $\mathrm{OH}$ at night? Phys. Chem. Chem. Phys., 8, 3749-3760, 2006.

von Friedeburg, C., Wagner, T., Geyer, A., Kaiser, N., Platt, U., Vogel, B. and Vogel, H.: Derivation of tropospheric $\mathrm{NO}_{3}$ profiles using off-axis differential optical absorption spectroscopy measurements during sunrise and comparison with simulations, J. Geophys. Res., 107(D13), 4168, doi:10.1029/2001JD000481, 2002.

Wallington, T. J., Dagaut, P., and Kurylo, M. J.: Ultraviolet absorption cross-sections and reaction kinetics and mechanisms for peroxy radicals in the gas phase, Chem. Rev., 92, 667-710, 1992.

Wallington, T. J., Gierczak, C. A., Ball, J. C., and Japar, S. M.: Fourier Transform Infrared studies of the self-reaction of $\mathrm{C}_{2} \mathrm{H}_{5} \mathrm{O}_{2}$ radicals in air at $295 \mathrm{~K}$, Int. J. Chem. Kinet., 21, 10771089, 1989.
Werner, G., Kastler, J., Looser, R., and Ballschmiter, K.: Organic nitrates of isoprene as atmospheric trace compounds, Angew. Chem. Int. Ed., 38(11), 1634-1637, 1999.

Wu, S. L., Mickley, L. J., Jacob, D. J. Logan, J. A., Yantosca, R. M., and Rind, D.: Why are there large differences between models in global budgets of tropospheric ozone? J. Geophys. Res., 112(D5), D05302, doi:10.1029/2006JD007801, 2007.

Zhang, D. and Zhang, R.: Unimolecular decomposition of nitrooxyalkyl radicals from $\mathrm{NO}_{3}$-isoprene reaction, J. Chem. Phys., 116(22), 9721-9728, 2002.

Ziemann, P.: Evidence for low-volatility diacyl peroxides as a nucleating agent and major component of aerosol formed from reactions of $\mathrm{O}_{3}$ with cyclohexene and homologous compounds, J. Phys. Chem., 106, 4390-4402, 2002. 